\title{
Influence of silver ion concentration on dielectric characteristics of $\mathrm{Li}_{2} \mathrm{O}-\mathrm{Nb}_{2} \mathrm{O}_{5}-\mathrm{P}_{2} \mathrm{O}_{5}$ glasses
}

\author{
V. Prasad ${ }^{1}$, L. Pavić ${ }^{2}$, A. Moguš-Milanković ${ }^{2}$ A. Siva Sesha Reddy ${ }^{1}$, Y. Gandhi ${ }^{3}$, \\ V. Ravi Kumar ${ }^{1^{*}}$, G. Naga Raju ${ }^{1}$, N. Veeraiah ${ }^{1 *}$ \\ ${ }^{1}$ Department of Physics, Acharya Nagarjuna University, Nagarjuna Nagar-522510, A.P., India \\ ${ }^{2}$ Ruđer Bošković Institute, Department of Chemistry, Zagreb, Croatia \\ ${ }^{3}$ Department of Physics, Kakani Venkata Ratnam College, Nandigama-521185, A.P., India.
}

\begin{abstract}
In this work we have studied the dielectric properties of $\mathrm{Li}_{2} \mathrm{O}-\mathrm{Nb}_{2} \mathrm{O}_{5}-\mathrm{P}_{2} \mathrm{O}_{5}: \mathrm{Ag}_{2} \mathrm{O}$ glasses as a function of $\mathrm{Ag}_{2} \mathrm{O}$ concentration. Auxiliary studies viz., optical absorption, photoluminescence (PL) and IR spectra have also been performed on these glasses. IR spectral studies have indicated that the host glass network doped with $1.0 \mathrm{~mol} \%$ of $\mathrm{Ag}_{2} \mathrm{O}$ is highly polymerized. Optical absorption and PL studies have clearly exhibited absorption and emission bands due to surface plasmon resonance (SPR). From these studies the presence of $\mathrm{Ag}^{0}-\mathrm{Ag}^{+}$clusters is established in the glass network and the concentration of such clusters is found to be the highest in the glass doped with $1.0 \mathrm{~mol} \%$ of $\mathrm{Ag}_{2} \mathrm{O}$. Finally, we have performed extensive studies on dielectric properties viz., dielectric constant, loss, electric moduli, impedance spectra and a.c. conductivity over broad ranges of frequency $(0.01$ $\mathrm{Hz}$ to $1 \mathrm{MHz}$ ) and temperature (303 to $513 \mathrm{~K}$ ). The glasses doped with higher content of $\mathrm{Ag}_{2} \mathrm{O}$ exhibited higher values of dielectric constant especially at lower frequencies and higher temperatures. The larger contribution from space charge polarization is predicted to be responsible for such higher values. In the glasses doped with low contents of $\mathrm{Ag}_{2} \mathrm{O}(<1.0 \mathrm{~mol} \%)$ the polaron conductivity (due to the polaronic transfer between $\mathrm{Ag}^{0}$ and $\mathrm{Ag}^{+}$ions) seemed to be dominant, whereas in the glasses containing more than $1.0 \mathrm{~mol} \%$ of $\mathrm{Ag}_{2} \mathrm{O}$, the ionic conduction (due to the diffusion of $\mathrm{Ag}^{+}$and $\mathrm{Li}^{+}$ ions) appeared to be prevailed. The impedance diagrams drawn between $Z^{\prime}$ and $Z^{\prime \prime}$ have further supported the above-mentioned conclusions. From the overall analysis of the results of dielectric properties (including a.c. conductivity ) with the aid of experimental results on spectroscopic studies, it is concluded that the glass containing more than $1.0 \mathrm{~mol} \%$ of $\mathrm{Ag}_{2} \mathrm{O}$ exhibited predominantly ionic conductivity and hence such glasses may be useful as electrolytes for ionic conducting batteries.
\end{abstract}

Keywords: $\mathrm{Li}_{2} \mathrm{O}-\mathrm{Nb}_{2} \mathrm{O}_{5}-\mathrm{P}_{2} \mathrm{O}_{5}$ glasses; Silver ions; Surface plasmon resonance; Dielectric properties

*Corresponding Authors: vrksurya@ rediffmail.com (V. Ravi Kumar), nvr8@ rediffmail.com (N. Veeraiah) 


\section{Introduction}

Lithium phosphate glasses when mixed with noble metal ions like Ag find potential applications as solid electrolytes in high-energy density batteries [1]. These materials were reported to exhibit mixed conduction viz., electronic and ionic and/or pure electronic or pure ionic conduction [2]. For this reason, these glasses are also being extensively used as cathodes in electrochemical cells, smart windows, etc. The electronic conduction or conduction due to polaron hopping is possible if these glasses are mixed with multivalent transitional metal oxides while the ionic conduction is predicted due to the transport of alkali ions as well as silver ions.

Moisture resistance of phosphate glasses can be improved if these glasses are mixed with intermediate glass forming transition metal oxides like $\mathrm{Nb}_{2} \mathrm{O}_{5}, \mathrm{Ta}_{2} \mathrm{O}_{5}, \mathrm{ZrO}_{2}$ etc. $\mathrm{Nb}-\mathrm{O}$ bond in $\mathrm{Nb}_{2} \mathrm{O}_{5}$ is predicted to be comparatively rigid with strong long-range Coulombic interaction. Such strong long-range interaction lowers the concentration of non-bridging oxygens to some extent and increase the corrosion resistance of the lithium phosphate glasses. $\mathrm{Nb}_{2} \mathrm{O}_{5}$ participates in the glass network with $\mathrm{NbO}_{4}$ (with $\mathrm{Nb}-\mathrm{O}$ bond length $\sim 1.823$ $\AA$ ) and also with $\mathrm{NbO}_{6}$ structural units (in which Nb-O bond length 1.977 ̊) [3]. Further, $\mathrm{Nb}_{2} \mathrm{O}_{5}$ mixed glasses are particularly useful for photocatalysts, as luminescent materials etc., and are also known as good dielectric materials [4-8].

The materials containing noble metallic particles exhibit surface plasmon resonance (SPR) due to the interaction with the incident electromagnetic waves; such interaction also aggregates metallic particles [9] in the host material. Due to the presence of these particles host material exhibit additional novel characteristics like catalytic activity, strong photoluminescence and also interesting changes in electrical properties [10-12]. The magnitude of resonance, however, depends on the size, shape, concentration of the noble metallic ions/particles and also on dielectric characteristics of the host material. Such special 
features make glasses useful for biosensors, for optical computing (because of their large non-linear optical response with ultra-fast response time). The response time for these materials is found to be in the range of picoseconds; this is an added advantage to enable processors with terahertz frequencies $[13,14]$. Majority of the previous studies on noble metal ions mixed glasses are restricted mainly to the optical properties.

The incident electromagnetic wave normally excites the combined oscillations of valence electrons of noble metal ions/particles present on the surface of the glasses and induce surface plasmon resonance. This type of resonance enhances local internal electric field in the surrounding positions of these noble metal ions significantly. The magnitude of the induced electric field is predicted to be 100 times more in the material when compared with the same excitation in the absence of plasmons [15]. Such strong induced electric fields are anticipated to influence the electrical characteristics substantially. Hence, studies on dielectric properties of ionic conducting materials over broad ranges of frequencies and temperatures of the materials that exhibit SPR is felt worth for investigation.

During melting and annealing processes of the glasses, there is a possibility for $\mathrm{Ag}^{+}$ ions to get converted into $\mathrm{Ag}^{0}$ or $\mathrm{Ag}^{2+}$ as intermediates, by electrochemical reduction and oxidation processes, respectively. Simultaneous presence of such silver ions and metallic particles in glass hosts further improves conductivity properties (contributes more to polaronic and ionic conductivities) and makes glasses more useful as electrolytes in solidstate batteries. Further, Ag particle clusters were proved to enhance mechanical stability of the glasses; this is a desirable property for a material to use in the design of nano-dimensional optoelectronic circuits and optical memory devices with very high recording speed and storage [16].

Even though, a considerable number of studies on several properties of silver oxide mixed phosphate glasses are available in the literature $[17,18]$, detailed investigations on 
electrical properties as such on $\mathrm{Nb}_{2} \mathrm{O}_{5}$ mixed lithium phosphate glasses with variable concentration of $\mathrm{Ag}_{2} \mathrm{O}$ and quantitative analysis of these results in terms of SPR and other spectroscopic studies are limited. $\mathrm{Li}_{2} \mathrm{O}$ is added since $\mathrm{Li}^{+}$ions are well known due to their significant contribution to the ionic conductivity. Further, $\mathrm{Li}_{2} \mathrm{O}$ also acts as a modifier, breaks the bindings between different phosphate structural units in the glass network and facilitates for the easy diffusion of conducting species including silver ions in the bulk glass.

Motivated by above described studies and predictions, present study is devoted to report the results of extensive studies on electrical properties (viz., the dielectric constant, dielectric loss, impedance spectra, dielectric relaxation kinetics and a.c conductivity over wide ranges of frequency and temperature) as a function of $\mathrm{Ag}_{2} \mathrm{O}$ concentration of $\mathrm{Li}_{2} \mathrm{O}$ $\mathrm{Nb}_{2} \mathrm{O}_{5}-\mathrm{P}_{2} \mathrm{O}_{5}$ and to explore the influence of $\mathrm{Ag}^{+}$ions on electrical characteristics of the titled glasses. The results of other auxiliary studies viz., optical absorption (SPR), PL and IR spectroscopic studies are also used for this purpose.

\section{Experimental}

Glass samples of chemical composition, viz., $35 \mathrm{Li}_{2} \mathrm{O}-5 \mathrm{Nb}_{2} \mathrm{O}_{5^{-}}(60-x) \mathrm{P}_{2} \mathrm{O}_{5^{-}} x \mathrm{Ag}_{2} \mathrm{O}$ (in mol \%) with $x$ varying from 0.5 to 2.5 in steps of $0.5 \mathrm{Ag}_{2} \mathrm{O}$, is chosen for the current study. The details of the composition are presented in Table 1.

The starting materials used for the preparation of the glasses were analytical grade reagents of $\mathrm{Li}_{2} \mathrm{CO}_{3}$ (99.9\% pure, Loba, Mumbai, India), $\mathrm{P}_{2} \mathrm{O}_{5}$ (99.99\% pure, Sigma Aldrich, Mumbai, India), $\mathrm{Nb}_{2} \mathrm{O}_{5}$ (99.9\% pure Sigma Aldrich, Mumbai, India) and $\mathrm{Ag}_{2} \mathrm{O}$ (99.99\% pure, Alfa Aesar, Massachusetts, USA). Powders of these compounds in appropriate proportions (all in mol\%) were thoroughly mixed in an agate mortar and melted in a platinum crucible in the temperature range $1150-1200{ }^{\circ} \mathrm{C}$ in a PID temperature-controlled furnace for about 30 min. till a clear liquid was formed. The resultant melt was then poured on rectangular brass mould and subsequently annealed at $350{ }^{\circ} \mathrm{C}$ in another furnace and cooled 
to ambient temperature at the rate of about $1{ }^{\circ} \mathrm{C} / \mathrm{min}$. The obtained samples were ground and optically polished to the final dimensions of about $1.0 \mathrm{~cm} \times 1.0 \mathrm{~cm} \times 0.2 \mathrm{~cm}$. Optical absorption spectra of the glasses were recorded at ambient temperature in the wavelength range $300-800 \mathrm{~nm}$ with a precision of $0.1 \mathrm{~nm}$ using a JASCO V-670 UV-Vis-NIR spectrophotometer. Photoluminescence spectra were recorded in the visible region using Thermo Scientific Luminescence Spectrophotometer. Infrared transmission spectra were recorded on a Shimadzu IR Affinity-1S FT-IR spectrophotometer up to a resolution of 0.1 $\mathrm{cm}^{-1}$ in the spectral range $400-1600 \mathrm{~cm}^{-1}$ using potassium bromide pellets. X-ray photoelectron spectroscopy (XPS) measurements were carried out on PHI 5000 Versa Probe ULVAC instrument with $\mathrm{Al} \mathrm{K}_{\alpha}(\mathrm{h} v=1486.6 \mathrm{eV}) \mathrm{X}$-ray source with reference to $\mathrm{C} 1 \mathrm{~s}$ peak at $284.6 \mathrm{eV}$. To minimize the effect of the electrostatic charge on the surface of the sample, a flood-gun was used. The precision in the measured energy value is $0.1 \mathrm{eV}$.

For electrical/dielectric measurements, gold electrodes of thickness $\sim 100 \mathrm{~nm}$ were deposited on to both sides of the samples using Sputter Coater SC7620. Dielectric properties were measured using Novo control Alpha-AN Dielectric impedance analyzer in the frequency range of $10^{-2}$ to $10^{6} \mathrm{~Hz}$ and in temperature range $303-513 \mathrm{~K}$. Temperature was controlled to an accuracy of $\pm 0.2 \mathrm{~K}$. Equivalent circuits modeling was employed to analyze the complex impedance plots and the corresponding parameters were determined by the Complex Nonlinear Least Squares (CNLLSQ) fitting procedure.

\section{Results and discussion}

Using the values of density $d$ and average molecular weight $\bar{M}$ of $\mathrm{Li}_{2} \mathrm{O}-\mathrm{Nb}_{2} \mathrm{O}_{5^{-}}$ $\mathrm{P}_{2} \mathrm{O}_{5}: \mathrm{Ag}_{2} \mathrm{O}$ glasses, $\mathrm{Ag}^{+}$ion concentration $N_{i}$ and mean $\mathrm{Ag}^{+}$ion separation $r_{i}$ are evaluated using the conventional formulae (mentioned in our recent report [19]) and are presented in Table 2. 
For having some preliminary understanding over the structural variations (which would be useful in analyzing the results of dielectric properties) taking place in the glass network due to the variation of $\mathrm{Ag}_{2} \mathrm{O}$ content, IR spectra of the titled glasses were recorded and presented in Fig. 1. The spectra exhibited vibrational bands at about 1250 and $1290 \mathrm{~cm}^{-1}$ identified as being due to anti-symmetrical vibrations of $\mathrm{PO}^{2-}$ and $\mathrm{P}=\mathrm{O}$ structural units, respectively. The spectra of all the glasses have also exhibited a feeble kink at about 1125 $\mathrm{cm}^{-1}$ assigned to the vibrations of $\mathrm{PO}_{3}{ }^{-}$structural units. The standard vibrational band due to $v_{3}$-symmetric stretchings of $\mathrm{PO}_{4}{ }^{3-}$ group is observed at about $1050 \mathrm{~cm}^{-1}$. The bands due to $\mathrm{P}-$ $\mathrm{O}-\mathrm{P}$ asymmetric bending vibrations and due to symmetric stretching vibrations are also located in the spectra at about $930 \mathrm{~cm}^{-1}$ and $770 \mathrm{~cm}^{-1}$, respectively [20-23]. Bands due to the vibrations of niobate structural units ascribed to $\mathrm{NbO}_{4}$ and $\mathrm{Nb}-\mathrm{O}-\mathrm{Nb}\left(v_{3}-\right.$ vibrations $)$ of $\mathrm{NbO}_{6}$ structural units are also detected in these spectra at about 900 and $560 \mathrm{~cm}^{-1}$, respectively [24].

With the gradual increase of $\mathrm{Ag}_{2} \mathrm{O}$ content up to $1.0 \mathrm{~mol} \%$, a significant increase in the intensity symmetrical bands of phosphate structural units and also that of $\mathrm{NbO}_{4}$ structural units could be visualized in these spectra. Moreover, bands due to the vibrations of $\mathrm{NbO}_{4}$ structural units and P-O-P units seemed to have been unresolved and exhibited a common vibrational band at about $900 \mathrm{~cm}^{-1}$ in the spectrum of $A_{10}$ glass. This feature of the spectrum qualitatively suggests possible linkages between phosphate and niobite structural units [25]. For further increase of $\mathrm{Ag}_{2} \mathrm{O}$ content, the common vibrational band appeared to be resolved into two separate bands and the vibrational bands due to asymmetrical vibrations of various phosphate structural units and also the intensity of the band due to $\mathrm{NbO}_{6}$ structural units is observed to be the minimal in the spectrum of the glass $A_{10}$ and observed to increase gradually with increase of $\mathrm{Ag}_{2} \mathrm{O}$ concentration beyond $1.0 \mathrm{~mol} \%$. Thus, the analysis of IR spectra suggests that in the network of the glass doped with $1.0 \mathrm{~mol} \%$ of $\mathrm{Ag}_{2} \mathrm{O}$ higher degree 
of connectivity between various structural units when compared to that of the glasses doped with higher concentrations of $\mathrm{Ag}_{2} \mathrm{O}$. The IR spectra have further revealed that the concentration of $\mathrm{NbO}_{4}$ structural units that cross-link with phosphate structural units is relatively higher in this glass. Unlike tetrahedral niobium ions, octahedral niobium ions do act as modifiers similar to $\mathrm{Li}_{2} \mathrm{O}$ and induce structural defects by breaking the continuous phosphate chains and increase the degree of disorder in the glass network [25].

It may be noted here most of the transition metal oxides (e.g., V, W, Mo, Ta, Fe, Co, $\mathrm{Ni}, \mathrm{Zr}, \mathrm{Cu}$, Ti including $\mathrm{Nb}$ ) when present in octahedral positions were reported to act as modifiers and induce structural defects in amorphous materials. From the studies on electrical properties, EPR spectra and even mechanical properties, such conclusion was drawn by many authors. On the other hand, if they are present in tetrahedral positions (with $\mathrm{MO}_{4}$ structural units) the host glass network acquires additional stability due to cross linking with these structural units [26-30].

In Fig. 2, we have presented the optical absorption spectra of $\mathrm{Li}_{2} \mathrm{O}-\mathrm{Nb}_{2} \mathrm{O}_{5}-\mathrm{P}_{2} \mathrm{O}_{5}$ glasses doped with different concentrations of $\mathrm{Ag}_{2} \mathrm{O}$ recorded at ambient temperature. In the spectra of all the glasses a feeble absorption kink (predicted to be due to the localized surface plasmon resonance (LSPR) of $\mathrm{Ag}^{0}$ particles is noticed at about $425 \mathrm{~nm}$. This band is found to be more intense especially in the spectrum of the glass doped with $1.0 \mathrm{~mol} \%$. We have already mentioned that the monovalent silver ions also act as electron trapping centers and get converted to unstable $\mathrm{Ag}^{0}\left(4 d^{10} 5 s^{1}\right)$ atoms. Such unstable atoms interact with $\mathrm{Ag}^{+}$ions and form stable $\mathrm{Ag}^{+}-\mathrm{Ag}^{0}$ clusters. The observed band in optical absorption spectra is in fact due to the resonance of coherent oscillations of conduction electrons on the surface of such clusters of silver particles and the incident electromagnetic waves [10,11,31,32]. Intensity and the half width of this band are observed to be the maximal in the spectrum of $\mathrm{Ag}_{10}$ glass; this observation suggests the higher dimensions of metallic silver particles in this glass. 
As per the mean-free-path theory, the FWHM, peak position and the intensity of surface-plasmon absorption resonance band strongly dependent on the particle size. If the size of the silver particles is very small (less than the wavelength of the incident light), the absorption peak shifts towards shorter wavelength and in such case the absorption is mainly due to dipolar absorption and the absorption cross-section is strongly dependent on dipole oscillations. This possibility seems to be responsible for the low intensity of this band observed in the spectra of the glasses doped with more than $1.0 \mathrm{~mol} \%$ of $\operatorname{Ag}_{2} \mathrm{O}$. On the other hand, if the size of the particles is larger, absorptions takes place due to multipoles viz., quadrupole, octupole. A small fraction of the contribution from the scattering to SPR band may also be possible due to the particles of larger dimensions [33-35].

The optical band gaps $\left(E_{o}\right)$ of the samples are evaluated by drawing Tauc plots (Fig. 3) between $(\alpha \hbar \omega)^{1 / 2} v s \hbar \omega$ as per the equation

$$
(\alpha \hbar \omega)=\mathrm{C}\left(\hbar \omega-E_{o}\right)^{2}
$$

and presented in Table 3. In Eq. (1), $\hbar \omega$ is the photon energy and $\mathrm{C}$ is temperature independent constant but depends on the refractive index $n$ of the glass. The value of $\mathrm{C}$ gives the information on the range of the extent of band tailing. It is given by

$$
C=(4 \pi c) \frac{\sigma_{0}}{n E_{U}}
$$

where $\sigma_{0}$ is the electrical conductivity at absolute zero and $E_{U}$ is the width of the tail of localized states in the normal forbidden gap.

The value of $E_{o}$ is estimated to be the highest for the glass doped with $1.0 \mathrm{~mol} \%$ of $\mathrm{Ag}_{2} \mathrm{O}$ and for further increase of $\mathrm{Ag}_{2} \mathrm{O}$, it is found to decrease. Reduction of $\mathrm{Ag}^{+}$ions to $\mathrm{Ag}^{0}$ leads to decrease in the concentration of donor centers. As a result, localized electrons that were trapped at $\mathrm{Ag}^{+}$states separate largely with the empty $5 d$ states of $\mathrm{Ag}^{0}$ sites. Due to these reasons, the width of energy band consisting of impurity (silver) energy states contracts in the main band gap and leads to the expansion of the optical band gap of the host glass with 
increase of $\mathrm{Ag}_{2} \mathrm{O}$ content up to $1.0 \mathrm{~mol} \%$. The IR spectral studies have also indicated that the concentration of tetrahedral niobium ions that form linkages with the phosphate structural units is the highest in the glass $\operatorname{Ag}_{10}$. Such linkages make the glass network more rigid and cause the optical band gap to increase.

We have also recorded the photoluminescence spectra of the titled glass excited at $390 \mathrm{~nm}$; the spectra exhibited a luminescence band in the blue region at about $445 \mathrm{~nm}$ with a considerable intensity. The intensity of this band is also observed to increase with the increase of $\mathrm{Ag}_{2} \mathrm{O}$ content from 0.5 to 1.0 mol\% with slight red shift (Fig. 4 (a)). This band is identified as being due to the excitation of silver ions from $\mathrm{Ag}^{0}-\mathrm{Ag}^{+}$clusters present in the glass [36]. Thus, the optical absorption and PL spectra, have clearly demonstrated a part of $\mathrm{Ag}^{+}$ions have been transformed into $\mathrm{Ag}^{0}$ particles during melting and annealing of the glasses and form $\mathrm{Ag}^{0}-\mathrm{Ag}^{+}$clusters.

For further confirmation of the presence of $\mathrm{Ag}^{+}$ions and $\mathrm{Ag}^{0}$ particles in the samples we have recorded XPS spectra and the obtained deconvolutional spectrum for one of the samples viz., $\mathrm{A}_{25}$ is presented in Fig. 4 (b). The spectrum exhibited conventional bands due to $\operatorname{Ag}^{+}\left(\operatorname{Ag~} 3 d_{3 / 2}\right)$ and $\operatorname{Ag}^{0}\left(\operatorname{Ag~} 3 d_{5 / 2}\right)$ particles at 367.3 and $373.2 \mathrm{eV}$, respectively [37]. This observation clearly confirms the presence of $\mathrm{Ag}^{0}$ metallic particles along with $\mathrm{Ag}^{+}$ions in the glass samples.

The variation of the real part of dielectric constant $\varepsilon^{\prime}(\omega)$ with frequency measured at different temperatures for the glass $A_{5}$ is presented in the Fig. 5(a), while in Fig. 5(b), the variation of $\varepsilon^{\prime}(\omega)$ with temperatures at different frequencies of glass $\mathrm{A}_{10}$ is presented. The variations exhibited significantly larger values at lower frequencies and the rate of increase of $\varepsilon^{\prime}(\omega)$ with temperatures is more distinct at such frequencies. The permittivity approached saturation values $\varepsilon_{\infty}$ at higher frequencies; this tendency is usually associated with the electronic polarization effects. 
The variation of dielectric constant of all the other samples with frequency and temperature exhibited similar behaviour. In the inset of Fig. 5(b), the variation of dielectric constant with the concentration of $\mathrm{Ag}_{2} \mathrm{O}$ measured at $333 \mathrm{~K}$ and $197.5 \mathrm{kHz}$ is presented; the variation exhibited the minimal value for the glass doped with $1.0 \mathrm{~mol} \%$ of $\operatorname{Ag}_{2} \mathrm{O}$.

The predominant contribution to the dielectric constant at lower frequencies is the space charge polarization that arises due to the accumulation of the free charge carriers from the bulk glass at the electrodes which obstruct the transfer of the charge species into the external circuit. Normally, the variation of $\varepsilon^{\prime}(\omega)$ with frequency is connected with the applied field that assists the hopping of the charge carriers between two different sites in the glasses. For these reasons, contribution to the dielectric constant at the lower frequencies of the applied field is much higher and causes to exhibit higher values of $\varepsilon^{\prime}(\omega)$. On the other hand, at higher frequencies, the charge carriers do not rotate at adequate speeds hence their oscillations lay behind the applied field and lead to decrease of dielectric permittivity, as has been observed in this study [37-40].

We have already mentioned that the degree of connectivity between various structural groups is the highest in the network of glass $\mathrm{A}_{10}$ when compared to that of the other glasses. The reasons are: (i) the presence of high concentration of $\mathrm{NbO}_{4}$ structural units (evidenced from IR spectra), (ii) the larger concentration of clusters of silver particles. Due to these reasons, there is an obstruction for the easy migration of the charge carriers that would build up space charge polarization at the electrodes. These factors account for the minimal value of dielectric constant observed for the glass $\mathrm{A}_{10}$.

Figs. 6(a) and 6(b) represent the variations of dielectric loss with frequency at different temperatures and with temperature at different frequencies for the glasses $\mathrm{A}_{15}$ and $\mathrm{A}_{20}$, respectively. These figures have indicated relaxation character of the dielectric loss. The dipolar effects sometimes may be masked or dominated by electrode polarization effects and 
hence the relaxation phenomenon exhibited by dielectric loss curves may not represent entirely the intrinsic dipolar effects. In such situations, the electrical modulus formalism is being extensively used for studying electrical relaxation behavior especially of ion conducting materials. In this representation, the electrode polarization effects are completely eliminated and the intrinsic dipolar effects of the samples can be more visualized. According to Mc Crum theory and subsequent modifications by Tsangaris et. al. [41], the complex electric modulus is defined as the reciprocal of complex permittivity:

$M^{*}(\omega)=\frac{1}{\varepsilon^{*}(\omega)}=M_{\infty}\left[1-\int_{0}^{\infty} \frac{-d \varphi(t)}{d t} \exp (-i \omega t) d t\right]=M^{\prime}(\omega)+\mathrm{i} M^{\prime \prime}(\omega)$

The real and imaginary parts of electric moduli for different distributions of relaxation times from Eq. (3) are represented by [41],

$$
\begin{aligned}
M^{\prime}(\omega) & =M_{\infty} M_{S} \frac{\left[M_{S} A^{\beta}+\left(M_{\infty}-M_{S}\right) \cos \beta \varphi\right] A^{\beta}}{M_{S}^{2} A^{2 \beta}+2 A^{\beta}\left(M_{\infty}-M_{S}\right) M_{S} \cos \beta \varphi+\left(M_{\infty}-M_{S}\right)^{2}} \\
& =\frac{\varepsilon^{\prime}(\omega)}{\left(\varepsilon^{\prime}(\omega)\right)^{2}+\left(\varepsilon^{\prime \prime}(\omega)\right)^{2}} \\
M^{\prime \prime}(\omega) & =M_{\infty} M_{S} \frac{\left[\left(M_{\infty}-M_{S}\right) \sin \beta \varphi\right] A^{\beta}}{M_{S}^{2} A^{2 \beta}+2 A^{\beta}\left(M_{\infty}-M_{S}\right) M_{S} \cos \beta \varphi+\left(M_{\infty}-M_{S}\right)^{2}} \\
= & \frac{\varepsilon^{\prime \prime}(\omega)}{\left(\varepsilon^{\prime}(\omega)\right)^{2}+\left(\varepsilon^{\prime \prime}(\omega)\right)^{2}} \cdot
\end{aligned}
$$

In the Eqs. (4) and (5), $M_{s}=1 / \varepsilon_{s} ; M_{\infty}=1 / \varepsilon_{\infty}$ and

$$
A=\left[1+2\left(\omega \tau_{0}\right)^{1-\alpha} \sin \left(\frac{\alpha \pi}{2}\right)+\left(\omega \tau_{0}\right)^{2(1-\alpha)}\right]^{1 / 2}
$$

Hence, to have a clear understanding on the dipole relaxation effects with the exclusion of electrode effects, we have estimated the real and imaginary components of electric moduli, $M^{\prime}(\omega)$ and $M^{\prime \prime}(\omega)$ using real and imaginary parts of dielectric constant at different temperatures as per the Eqs. (4) and (5) for $\mathrm{Li}_{2} \mathrm{O}-\mathrm{Nb}_{2} \mathrm{O}_{5}-\mathrm{P}_{2} \mathrm{O}_{5}: \mathrm{Ag}_{2} \mathrm{O}$ glasses and their variations with frequency at different temperatures (in the range $303 \mathrm{~K}-513 \mathrm{~K}$ ) for a 
selected glass $\left(A_{15}\right)$ are presented in the Figs. 7(a) and 7(b), respectively. In the Figs. 8(a) and 8(b), variations of $M^{\prime}(\omega)$ and $M^{\prime \prime}(\omega)$ with temperature at different frequencies (in the range $0.01 \mathrm{~Hz}$ to $1 \mathrm{MHz}$ ) for the glass $\mathrm{A}_{20}$ are presented, respectively. The variations have confirmed the perfect relaxation features. The real part of electric modulus $M^{\prime}(\omega)$ increased with increasing frequency and at sufficiently higher frequencies it reached a saturation corresponding to the limiting value of $M^{\prime}{ }_{\infty}$. Such trend suggests the observed relaxation effects are purely due to intrinsic dipoles of the samples and there is no influence of electrode effects on relaxation phenomenon [41].

The average activation energy for the dipoles, $W_{d}$, is calculated from the Arrhenius' plots drawn between $\log$ of relaxation frequency maxima $\left(f_{\max }\right)$ of $M^{\prime \prime} v s 1 / T$ based on

$$
f=f_{0} e^{\frac{-W_{d}}{k T}}
$$

where, $f_{0}$ is a constant and $k$ is the Boltzmann constant. The obtained values of $W_{d}$ for all the glass samples are presented in Table 4. The variation of $W_{d}$ with the concentration of $\operatorname{Ag}_{2} \mathrm{O}$ exhibited convex behavior at $\mathrm{x}=1.0 \mathrm{~mol} \%$. This result suggests that the degree of freedom for dipoles to orient in the field direction is the lowest in this glass when compared with that of other glasses.

From the point of intersection of $M^{\prime}(\omega)$ and $M^{\prime \prime}(\omega)$ at $\left(M^{\prime \prime}\right)_{\max }$ (Fig. 9(a)) drawn at 363 $\mathrm{K}$ for the sample $\left.\mathrm{A}_{15}\right)$, the relaxation time $\left(\tau_{M}=1 / \omega_{m}\right)$ for dipoles is evaluated for all the glasses and its variation with the concentration of $\mathrm{Ag}_{2} \mathrm{O}$ is presented in Fig. 9(b); the value of $\tau_{M}$ is observed to be the maximum for the glass $\mathrm{A}_{10}$. Further, the variation of relaxation time with temperature for any given sample exhibited a decreasing trend with increase of temperature. Moreover, the value of $\tau_{M}$ is observed to decrease at faster rates in the low temperature region while it is found to be nearly temperature independent in the high temperature region (Fig. 9(c)). These results clearly demonstrated that the spreading of 
relaxation times and the degree of spreading is higher in the low temperature region. The spreading of relaxation times suggests that the dipolar effects are due to multiple types of dipoles that have got different magnitudes of dipole moments [42, 43]. Even if there is one kind of dipoles, the dipoles experience random potential energy on diffusing through the distorted structure of the glass network; due to this reason there is also a possibility for the spreading of relaxation times [44]. Normally, in silver doped glasses, complexes of divalent silver ions (if any) with oxygens do contribute to the relaxation effects. Additionally, in several other phosphate glass systems, it was reported that even $\mathrm{PO}_{2}{ }^{-}$complexes do possess the net dipole moment and contribute to these relaxation effects [45].

To estimate the magnitude of the electrical impedance or the conductivity of the titled glasses, we have plotted real and imaginary parts of electrical impedance (measured at different frequencies) at different temperatures. Figs. 10 (a, b, c and d) represents such impedance diagrams (also known as Nyquist plots) for the glass $\mathrm{A}_{25}$ drawn at some selected temperatures. The diagrams appeared to be semicircles and with increase of temperature the area under the semicircle is observed to be decreasing. This trend suggests the decreasing magnitude of impedance or increasing magnitude of the conductivity with increasing temperature. Further, the center of the semicircle appeared to be lying below the X-axis. This observation also suggests the spreading of relaxation times of the dipoles.

In Fig. 11, we have shown the comparison plots of impedance spectra for all the glasses drawn at $453 \mathrm{~K}$. The area under the semicircles is found to be the highest for the glasses mixed with $1.0 \mathrm{~mol} \%$ of $\mathrm{Ag}_{2} \mathrm{O}$; this result suggests large bulk impedance or low conductivity of this glass. Further, the impedance diagrams have exhibited an inclined spur in the low frequency side due to electrode polarization [46]. The magnitude of this spur is observed to be the minimal for the glass $\mathrm{A}_{10}$ (Fig. 11). This result indicates the thermally stimulated mobility of conducting species is the lowest in this glass. 
In Figs. 12(a) and (b), we have presented the variation of a.c. conductivity, $\sigma_{a c}$ with frequency at different temperatures and with $1 / T$ at different frequencies for the glass $\mathrm{A}_{20} . \sigma_{\mathrm{ac}}$, in the in the low frequency region and at higher temperature it is observed to be nearly independent of frequency and it represents the dc conductivity, $\sigma_{\mathrm{dc}}$. However, at higher frequency (and in the lower temperature regions) it exhibited dispersion spread over in power-law fashion.

The universal dielectric response (UDR) [47] of the frequency dependent electrical conductivity is presented by,

$$
\sigma(\omega)=\sigma_{d c}+\omega^{n}+\omega^{s}
$$

In Eq. (8), as $\omega \rightarrow 0, \sigma(\omega) \rightarrow \sigma_{d c}$ and as $\omega \rightarrow \infty, \sigma(\omega) \propto \omega^{\mathrm{n}}$ with $\mathrm{n} \approx 1$. In the middle frequency region, the conductivity is increased in a sublinear fashion. In this frequency region, ion transport is characterized by the non-random forward-backward hopping process (due to the Coulomb repulsive interaction between mobile carriers) from its initial site. In such cases, the mean square displacement of ions is negligibly small. Then Eq. (8) indicates

$$
\sigma(\omega) \propto \omega^{s}
$$

The exponent $s$ depends on the ratio of front to back- hop rate and also relaxation rate of initial state of conducting ions. We have evaluated the UDR exponent $s$ from the plots of $\log \sigma_{a c}(\omega) v s \log \omega$. Fig. 13 represents such plot for the glass $\mathrm{A}_{15}$ at different temperatures in middle frequency region. The values of $s$ evaluated from these plots are found to be lower at higher temperatures. Such trend indicates the conductivity is connected with the polaron hopping at higher temperatures [48]. The variation of $s$ with the concentration of $\mathrm{Ag}_{2} \mathrm{O}$ (evaluated at $303 \mathrm{~K}$ ) is shown in the inset of Fig. 13. The value of $s$ exhibited the maximum at $\mathrm{x}=1.0 \mathrm{~mol} \%$ (at any temperature) and for further increase of $\mathrm{Ag}_{2} \mathrm{O}$ concentration, it is observed to increase. Such trend suggests that polaronic conductivity is the dominant one in 
the glass $\mathrm{A}_{10}$ and for further increase of $\mathrm{Ag}_{2} \mathrm{O}$ the variation indicates that the ionic conductivity prevails over the polaron hopping [43].

The studies of optical absorption and photoluminescence spectra, have indicated that the silver particles exist in $\mathrm{Ag}^{0}$ and $\mathrm{Ag}^{+}$states and the concentration of the clusters of such particles is the maximum in the glass $A_{10}$. The highest intensity of SPR band observed for this glass, in fact, supports this view point. Hence, one can predict more probability for the transfer of polarons between silver metallic particles and monovalent silver ions in this glass. This argument suggests that the conductivity in the glasses containing $\mathrm{Ag}_{2} \mathrm{O}$ up to $1.0 \mathrm{~mol} \%$ is predominantly due to polaron hopping.

The higher values of $s$ observed for the glasses doped with more than $1.0 \mathrm{~mol} \%$ of $\mathrm{Ag}_{2} \mathrm{O}$ point out that ionic contribution to the conductivity prevails. It is general understanding that in lithium phosphate glasses, lithium ions (because of their smaller size and high mobility) contribute to the ionic conduction. In the present case the ionic contribution is naturally due to diffusion of $\mathrm{Li}^{+}$and $\mathrm{Ag}^{+}$ions in the glass matrix. The magnitude of such diffusion is more in these glasses. We have already mentioned that the concentration of $\mathrm{NbO}_{4}$ structural units (that makes the glass network more rigid) is lower or the concentration of octahedral $\mathrm{Nb}$ ions that induce structural defects (similar to $\mathrm{Li}^{+}$and $\mathrm{Ag}^{+}$ions) like nonbridging oxygens, dangling bonds etc., in the glass network is higher in the glass containing $\mathrm{Ag}_{2} \mathrm{O}$ beyond $1.0 \mathrm{~mol} \%$. In other words, the degree of depolymerization of glass network is higher in these glasses and pave the way for easy transport of charge carriers over the long ranges in the glass network.

From the plots of $\log \sigma_{\mathrm{ac}} v s 1 / T$, we have evaluated the activation energy $W_{\mathrm{ac}}$ for the conduction for all the glasses and its variation with the concentration $\operatorname{Ag}_{2} \mathrm{O}$ is presented in Fig. 14. In the same figure the variation of a.c. conductivity with the concentration of $\operatorname{Ag}_{2} \mathrm{O}$ is presented. As mentioned earlier $\sigma_{\mathrm{ac}}$ exhibited the minimal while the activation energy is found 
to be maximal for the glass mixed with $1.0 \mathrm{~mol} \%$. This observation also clearly demonstrates

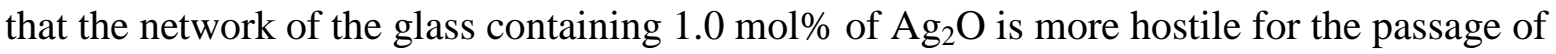
the free charge carriers.

A.C. conductivity at low-temperatures and at slightly higher frequency region is observed to be nearly temperature independent. The conductivity in such regions can be explained by the standard quantum mechanical tunneling (QMT) model [43]. According to this model,

$$
\sigma(\omega)=\frac{\pi}{3} e^{2} k_{B} T\left[N\left(E_{F}\right)\right]^{2} \alpha^{-5} \omega\left[\ln \frac{v_{p h}}{\omega}\right]^{4}
$$

where $N\left(E_{F}\right)$ is the density of defect energy states near the Fermi level and the other symbols were explained in our earlier Refs. [37, 38]. We have evaluated the values of $N\left(E_{F}\right)$ using Eq. (10) at a frequency of $296 \mathrm{kHz}$, and $\mathrm{T}=333 \mathrm{~K}$, with the average value of $\alpha=0.54(\AA)^{-1}$ (evaluated by plotting $\log \sigma_{a c}$ against $R_{i}$ ) and presented in Table 4 . The concentration of defect energy states is found to be the minimal for the glass $A_{10}$ which is once again in supportive of the conclusion that the network of this glass is more rigid and less conducive for transport of charge carriers. On the other hand, the glasses doped with larger concentration of $\mathrm{Ag}_{2} \mathrm{O}$ (beyond $1.0 \mathrm{~mol} \%$ ) exhibited higher magnitude of ionic conductivity.

\section{Conclusions}

We have prepared $\mathrm{Li}_{2} \mathrm{O}-\mathrm{Nb}_{2} \mathrm{O}_{5}-\mathrm{P}_{2} \mathrm{O}_{5}$ glasses doped with different concentrations of $\mathrm{Ag}_{2} \mathrm{O}$ and their dielectric properties were studied over broad ranges of frequencies and temperatures. As a part of having some pre-structural understanding spectroscopic studies (viz., optical absorption, IR and photoluminescence spectral studies) have also been carried out. Optical absorption and PL spectral studies have indicated the presence of the clusters of silver metallic particles and $\mathrm{Ag}^{+}$ions that cause surface plasmon resonance with the incident electromagnetic wave. The concentration of such clusters is the highest in the glass doped 
with $1.0 \mathrm{~mol} \%$ of $\mathrm{Ag}_{2} \mathrm{O}$. IR spectral studies have indicated an increase in the degree of depolymerization of the glass network or increase in the concentration of structural defects in the glass network with increase of $\mathrm{Ag}_{2} \mathrm{O}$ content beyond $1.0 \mathrm{~mol} \%$. Variations of dielectric constant with the concentration of $\mathrm{Ag}_{2} \mathrm{O}$ exhibited the minimal values at $1.0 \mathrm{~mol} \%$ of $\mathrm{Ag}_{2} \mathrm{O}$ and for further increase of this dopant concentration, the values of $\varepsilon^{\prime}(\omega)$ are found to be higher. Dielectric relaxation effects exhibited by dielectric loss as well as electric moduli were quantitatively discussed and the observed spreading of relaxation times with the concentration of $\mathrm{Ag}_{2} \mathrm{O}$ was attributed to the presence of multiple types of dipoles in the glass samples. In the glass samples containing low content of $\mathrm{Ag}_{2} \mathrm{O}$ (up to $1.0 \mathrm{~mol} \%$ ) a.c. conductivity is predicted to be mainly due to the polaron hopping between silver metallic particles and $\mathrm{Ag}^{+}$ions. In the samples containing larger concentration of $\mathrm{Ag}_{2} \mathrm{O}$, ionic conductivity seems to be prevailing and it is attributed to the diffusion of $\mathrm{Ag}^{+}$and $\mathrm{Li}^{+}$ions. The overall analysis of the results suggested that the contribution to the conductivity is mainly ionic in character in the samples containing higher content of $\operatorname{Ag}_{2} \mathrm{O}$ and hence such samples may be useful for considering these materials in solid state batteries as electrolytes.

\section{Acknowledgments}

L. Pavic and A. Moguš-Milanković would like to acknowledge funding from the Croatian Science Foundation; project IP-09-2014-5863. A. Siva Sesha Reddy thanks UGC, New Delhi, for sanctioning BSR fellowship to carry out this work. N. Veeraiah wishes to thank UGC, New Delhi, for sanctioning BSR Faculty fellowship to carry out this work. 


\section{References}

[1] M. Nagarjuna, P. Raghava Rao, Y. Gandhi, V. Ravi Kumar, N. Veeraiah, Electrical conduction and other related properties of silver ion doped $\mathrm{LiF}-\mathrm{V}_{2} \mathrm{O}_{5}-\mathrm{P}_{2} \mathrm{O}_{5}$ glass system, Physica B 405 (2010) 668-677.

[2] A. Chatterjee, A. Ghosh, Correlation between ion transport and network structure of $\mathrm{Li}_{2} \mathrm{O}-\mathrm{P}_{2} \mathrm{O}_{5}$ glasses, Solid State Ionics 314 (2018) 1-8

[3] R.C.C. Monteiro, A.A.S. Lopes, M.M.R.A. Lima, J.P.B. Veiga, Thermal characteristics and crystallization behavior of zinc borosilicate glasses containing $\mathrm{Nb}_{2} \mathrm{O}_{5}$, J. Non-Cryst. Solids 491 (2018) 124-132.

[4] J. Liu, K. Yang, J. Zhai, B. Shen, Effects of crystallization temperature on phase evolution and energy storage properties of $\mathrm{BaO}-\mathrm{Na}_{2} \mathrm{O}-\mathrm{Nb}_{2} \mathrm{O}_{5}-\mathrm{SiO}_{2}-\mathrm{Al}_{2} \mathrm{O}_{3}$ glassceramics, J. Euro. Ceram. Soc. 38 (2018) 2312-2317.

[5] K. Yang, J. Liu, B. Shen, J. Zhai, H. Wang, Large improvement on energy storage and charge-discharge properties of $\mathrm{Gd}_{2} \mathrm{O}_{3}$-doped $\mathrm{BaO}-\mathrm{K}_{2} \mathrm{O}-\mathrm{Nb}_{2} \mathrm{O}_{5}-\mathrm{SiO}_{2}$ glass-ceramic dielectrics, Mater. Sci. Eng. B 223 (2017) 178-184.

[6] S. Lee, H. Maeda, A. Obata, K. Ueda, T. Narushima, T. Kasuga, Structures and dissolution behaviors of MgO-CaO-P2O5-Nb2O5 glasses, J. Non-Cryst. Solids 438 (2016) 18-25.

[7] Y. Attafi, S. Liu, Conductivity and dielectric properties of $\mathrm{Na}_{2} \mathrm{O}-\mathrm{K}_{2} \mathrm{O}-\mathrm{Nb}_{2} \mathrm{O}_{5}-\mathrm{P}_{2} \mathrm{O}_{5}$ glasses with varying amounts of $\mathrm{Nb}_{2} \mathrm{O}_{5}$, J. Non-Cryst. Solids 447 (2016) 74-79.

[8] A. Gholami, T.N. Amirabad, M. Maddahfar, Investigation of photovoltaic properties of silver-doped $\mathrm{ZnTiO}_{3}$ nanoparticles, J. Mater. Sci. 3 (2017)15327-15332.

[9] D.S. Rahman, S.K. Ghosh, Fluorescence spectroscopy in probing spontaneous and induced aggregation amongst size-selective gold nanoclusters, Chem. Phys. 438 (2014) 66-74.

[10] Y. Fang, B. Zhang, L. Hong, K. Zhang, G. Li, J. Jiang, R. Yanc, J. Chen, Mechanism of photocatalytic activity improvement of $\mathrm{AgNPs} / \mathrm{TiO} 2$ by oxygen plasma irradiation, Nanoscale 8 (2016) 17004-17011.

[11] K. Sklepić, M. Vorokhta, P. Mošner, L. Koudelka, A.M. Milanković, Electrical Mobility of Silver Ion in $\mathrm{Ag}_{2} \mathrm{O}-\mathrm{B}_{2} \mathrm{O}_{3}-\mathrm{P}_{2} \mathrm{O}_{5}-\mathrm{TeO}_{2}$ Glasses, J. Phys. Chem. B 118 (2014) 12050-12058.

[12] Z.M. Fard, M. Bagheri, H.Z. Mousavi, S. Rabieh, Plasmonic Ag/Ag2O nanoparticles anchored needle-like $\mathrm{Bi} 2 \mathrm{O} 3$ as an efficient visible-light-driven nanocomposite photocatalyst, Mater. Res. Bull. 101 (2018) 311-318.

[13] L. Jun, Z. Yang, B. Shao, J. Yang, Y. Wang, J. Qiu, Z. Song, Photoluminescence enhancement of $\mathrm{SiO}_{2}$-coated $\mathrm{LaPO}_{4}: \mathrm{Eu}^{3+}$ inverse opals by surface plasmon resonance of Ag nanoparticles, J. Am. Ceram. Soc. 99 (2016) 3330-3335. 
[14] Q. Wu, M. Si, B. Zhang, K. Zhang, H. Li, L. Mi, Y. Jiang, Y. Rong, J. Chen, Y. Fang, Strong damping of the localized surface plasmon resonance of Ag nanoparticles by $\mathrm{Ag}_{2} \mathrm{O}$, Nanotechnology 29 (2018) 295702.

[15] B. Sahu, R. Dey, P.K. Bajpai, $\mathrm{Au}^{3+}$ ion implantation on FTO coated glasses: Effect on structural, electrical, optical and phonon properties, Nucl. Instr. Meth. Phys. Res. B 400 (2017) 11-21.

[16] Q. Zhang, Z. Xia, Yi-Bing Cheng, and M. Gu, High-capacity optical long data memory based on enhanced Young's modulus in nanoplasmonic hybrid glass composites, Nat. Commun. 9 (2018) 1183.

[17] L. Pavic, A. Santic, J, Nikolic, P. Mosner, L. Koudelka, D. Pajic, A.M. Milankovic, Nature of mixed electrical transport in $\mathrm{Ag}_{2} \mathrm{O}-\mathrm{ZnO}-\mathrm{P}_{2} \mathrm{O}_{5}$ glasses containing $\mathrm{WO}_{3}$ and $\mathrm{MoO}_{3}$, Electrochim. Acta 276 (2018) 434-445.

[18] B. Eraiah, R.V. Anavekar, Elastic properties of silver-phospho-vanadate glasses, J. Alloys Compd. 489 (2010) 325-327.

[19] J. Ashok, M. Kostrzewa, M. Srinivasa Reddy, V. Ravi Kumar, N. Venkatramiah, M. Piasecki, N. Veeraiah, Structural and physical characteristics of $\mathrm{Au}_{2} \mathrm{O}_{3}$-doped sodium antimonate glasses-part I, J. Am. Ceram. Soc. (2018) DOI: 10.1111/jace.16013.

[20] A. Saitoh, R.K. Brow, U. Hoppe, G. Tricot, S. Anan, H. Takebe, The structure and properties of $\mathrm{xZnO}-(67-\mathrm{x}) \mathrm{SnO}-\mathrm{P}_{2} \mathrm{O}_{5}$ glasses: (I) optical and thermal properties, Raman and infrared spectroscopies, J. Non-Cryst. Solids 484 (2018) 132-138.

[21] Ch. Vijaya Kumari, P. Sobhanachalam, C.K. Jayasankar, N. Veeraiah, V. Ravi Kumar, Bioactive properties of $\mathrm{CuO}$ doped $\mathrm{CaF}_{2}-\mathrm{CaO}-\mathrm{B}_{2} \mathrm{O}_{3}-\mathrm{P}_{2} \mathrm{O}_{5}-\mathrm{MO}(\mathrm{M}=\mathrm{Ba}, \mathrm{Sr}, \mathrm{Zn}, \mathrm{Mg})$ glasses, Ceram. Int. 43 (2017) 4335-4343

[22] V. Ravi Kumar, G. Giridhar, V. Sudarsan, N. Veeraiah, Influence of red lead on the intensity of green and orange emissions of $\mathrm{Sm}^{3+}$ and $\mathrm{Ho}^{3+}$ co-doped $\mathrm{ZnO}-\mathrm{SrO}-\mathrm{P}_{2} \mathrm{O}_{5}$ glass system J. Alloys Compd. 695 (2017) 668-681.

[23] N. Kitamura, K. Yamanaka, T. Yaji, T. Ohta, Effects of fluorine substitution on structural and optical properties of $\mathrm{ZnO}-\mathrm{Bi}_{2} \mathrm{O}_{3}-\mathrm{P}_{2} \mathrm{O}_{5}$ glass, J. Non-Cryst. Solids 499 (2018) 62-65.

[24] S. Rajkumar, P. Abdul Azeem, P. Vasudevarao, M. Bramanandam, In vitro evaluation of niobia added soda lime borosilicate bioactive glasses, J. Alloys Compd. 764 (2018) 1072-1078.

[25] S. Lee, A.L.B. Maçon, T. Kasuga, Structure and dissolution behavior of orthophosphate $\mathrm{MgO}-\mathrm{CaO}-\mathrm{P}_{2} \mathrm{O}_{5}-\mathrm{Nb}_{2} \mathrm{O}_{5}$ glass and glass-ceramic, Mater. Lett. 175 (2016) 135-138.

[26] A. Subba Rao, J. Ashok, B. Suresh, G. Naga Raju, N. Venkatramaiah, V. Ravi Kumar, I.V. Kityk, N. Veeraiah, Physical characteristics of $\mathrm{PbO}-\mathrm{ZrO}_{2}-\mathrm{SiO}_{2}: \mathrm{TiO}_{2}$ glass ceramics embedded with $\mathrm{Pb}_{2} \mathrm{Ti}_{2} \mathrm{O}_{6}$ cubic pyrochlore crystal phase: Part-I Electrical properties, J. Alloys Compd. 712 (2017) 672-686. 
[27] V. Prasad, B. Suresh, M. Kostrzewa, Y. Gandhi, A. Ingram A. Siva Sesha Reddy,V. Ravi Kumar, N. Veeraiah, Dielectric dispersion, dipolar relaxation and a.c. conduction phenomena of $\mathrm{NiO}$ doped lead bismuth silicate glass system, J. Non-Cryst. Solids (2018) doi: 10.1016/j.jnoncrysol.2018.09.002

[28] A. Siva Sesha Reddy, A. Ingram, M.G. Brik, M. Kostrzewa, P. Bragiel, V. Ravi Kumar and N. Veeraiah, Insulating characteristics of zinc niobium borate glass ceramics, $\mathrm{J}$. Am. Ceram. Soc. 100 (2017) 4066-4080.

[29] A. Siva Sesha Reddy, M.G. Brik, J. Suresh Kumar, M.P.F. Graca, G. Naga Raju, V. Ravi Kumar, M. Piasecki, N. Veeraiah, Structural and electrical properties of zinc tantalum borate glass ceramic, Ceram. Int. 42 (2016) 17269-17282.

[30] A. Siva Sesha Reddy, M. Kostrzew A. Ingram, N. Purnachand, P. Bragiel, V. Ravi Kumar, I.V. Kityk, N. Veeraiah, Positron annihilation exploration of voids in zinc zirconium borate glass ceramics entrenched with $\mathrm{ZnZrO}_{3}$ perovskite crystal phases, $\mathrm{J}$. Euro. Ceram. Soc. 38 (2018) 2010-2016.

[31] V.M. Renteria, J. Garcia-Macedo, Modeling of optical absorption of silver prolate nanoparticles stabilized by Gemini surfactant, Colloids Surf. A 273 (2006) 1-3.

[32] E. Saion, E. Gharibshahi, K. Naghavi, Size-controlled and optical properties of monodispersed silver nanoparticles synthesized by the radiolytic reduction method, Int. J. Mol. Sci. 14 (2013) 7880-7896.

[33] J.P. Juste, I.P. Santos, L.M.L. Marzán, P. Mulvaney, Gold nanorods: synthesis, characterization and applications, Coord. Chem. Rev. 249 (2005) 1870-1901.

[34] M. Manoth, K. Manzoor, M.K. Patra, P. Pandey, S.R. Vadera, N. Kumar, Dendrigraft polymer-based synthesis of silver nanoparticles showing bright blue fluorescence, Mater. Res. Bull. 44 (2009) 714-717.

[35] E. Culea, P. Pascuta, M. Pustan, D. R. Tamas-Gavrea, L. Pop, I. Vida-Simiti, Effects of Eu:Ag codoping on structural, magnetic and mechanical properties of lead tellurite glass ceramics, J. Non-Cryst. Solids 408 (2015) 18-25.

[36] M. Manoth, K. Manzoor, M.K. Patra P. Pandey, S.R. Vadera, N. Kumar, Dendrigraft polymer-based synthesis of silver nanoparticles showing bright blue fluorescence, Mater. Res. Bull. 44 (2009) 714-717.

[37] R. Vijay, L. Pavić, A. Šantić, A. Moguš-Milanković, P. Ramesh Babu, D. Krishna Rao, V. Ravi Kumar, N. Veeraiah, Influence of tungsten ions valence states on electrical characteristics of quaternary lithium-antimony-lead-germanate glasses, J. Phys. Chem. Solids 107 (2017) 108-117.

[38] K. Naresh Kumar, M. Kostrzewa, Adam Ingram, B. Suresh, A. Siva Sesha Reddy, Y. Gandhi, M. Piasecki, N. Veeraiah, Dielectric features, relaxation dynamics and a.c. conductivity studies on $\mathrm{Ag}^{+}$mixed lead arsenate glass ceramics, J. Mater. Sci.- Mater. Elect. 29 (2018) 1153-1172. 
[39] G. Ravi Kumar, M. Koteswara Rao, T. Srikumar, M.C. Rao, V. Ravi Kumar, N. Veeraiah, Ch. Srinivasa Rao, Spectroscopic, dielectric dispersion and dc conductivity studies of $\mathrm{Sb}_{2} \mathrm{O}_{3}$ doped lithium fluoro borophosphate glasses mixed with small concentrations of NiO, J. Alloys Compd. 752 (2018) 179-190

[40] L. Pavić, A. Moguš-Milanković, P. Raghava Rao, A. Šantić, V. Ravi Kumar, N. Veeraiah, Effect of modifier ion on electrical, dielectric and spectroscopic properties of $\mathrm{Fe}_{2} \mathrm{O}_{3}$ doped sodium sulfo phosphate glass system, J. Alloys Compd. 604 (2014) 352362.

[41] G.C. Psarras, E. Manolakaki, G.M. Tsangaris, Electrical relaxations in polymeric particulate composites of epoxy resin and metal particles, Compos. Part A: Appl. Sci. Manuf. 33 (2002) 375-384.

[42] A.Subba Rao, J. Ashok, B. Suresh, G. Naga Raju, N. Venkatramaiah, V. Ravi Kumar, I.V. Kityk, N. Veeraiah Physical characteristics of $\mathrm{PbO}-\mathrm{ZrO}_{2}-\mathrm{SiO}_{2}: \mathrm{TiO}_{2}$ glass ceramics embedded with $\mathrm{Pb}_{2} \mathrm{Ti}_{2} \mathrm{O}_{6}$ cubic pyrochlore crystal phase: Part-I Electrical properties, J. Alloys Compd. 712 (2017) 672-686.

[43] J. Ashok, N. Purnachand J. Suresh Kumar M. Srinivasa Reddy, B. Suresh, M.P.F. Graca, N. Veeraiah Studies on dielectric dispersion, relaxation kinetics and a.c. conductivity of $\mathrm{Na}_{2} \mathrm{O}-\mathrm{CuO}-\mathrm{SiO}_{2}$ glasses mixed with $\mathrm{Bi}_{2} \mathrm{O}_{3}$-Influence of redox behavior of copper ions, J. Alloys Compd. 696 (2017) 1260-1268.

[44] K. Naresh Kumar, B. Suresh, A. Ingram, M. Kostrzewa, P. Bragiel, V. Ravi Kumar, N. Veeraiah Investigations on electrical characteristics of $(\mathrm{PbO})_{30}(\mathrm{CuO})_{\mathrm{x}}\left(\mathrm{As}_{2} \mathrm{O}_{3}\right)_{(70-\mathrm{x})}$ glass ceramics, Ceram. Int. 43 (2017) 4335-4343.

[45] P. Rajanikanth M.A. Valente, Y. Gandhi, M. Piasecki, N. Veeraiah Influence of tin ions on a.c. conductivity and dielectric features of $\mathrm{Li}_{2} \mathrm{O}-\mathrm{PbO}-\mathrm{P}_{2} \mathrm{O}_{5}$ glass system, Ionics 21 (2015) 3051-3063

[46] A.M. Milanković, L. Pavić, K. Srilatha, Ch. Srinivasa Rao, T. Srikumar, Y. Gandhi, and N. Veeraiah, Electrical, dielectric and spectroscopic studies on MnO doped LiI-AgI$\mathrm{B}_{2} \mathrm{O}_{3}$ glasses, J. Appl. Phys. 111 (2012) 013714.

[47] J. Zhang, D.Y. Xu, L. Tong, H.C. Qi, D.L. Zhang, C.C. Wang, Surface layer and its effect on dielectric properties of SiC ceramics, J. Alloys Compd. 734 (2018) 16-21.

[48] P. Kupracz, A. Lenarciak, M. Lapinski, M. Przesniak- Welenc, N.A. Wojcik, R.J. Barczynski, Polaron hopping conduction in manganese borosilicate glass, J. Non-Cryst. Solids 458 (2017) 15-21. 


\section{Captions for Tables}

Table 1. Composition (all in mol\%) and thickness of the glass samples used.

Table 2. Physical properties of $\mathrm{Li}_{2} \mathrm{O}-\mathrm{Nb}_{2} \mathrm{O}_{5}-\mathrm{P}_{2} \mathrm{O}_{5}: \mathrm{Ag}_{2} \mathrm{O}$ glasses.

Table 3. Optical bandgaps of $\mathrm{Li}_{2} \mathrm{O}-\mathrm{Nb}_{2} \mathrm{O}_{5}-\mathrm{P}_{2} \mathrm{O}_{5}: \mathrm{Ag}_{2} \mathrm{O}$ glasses.

Table 4. Selected dielectric parameters for $\mathrm{Li}_{2} \mathrm{O}-\mathrm{Nb}_{2} \mathrm{O}_{5}-\mathrm{P}_{2} \mathrm{O}_{5}: \mathrm{Ag}_{2} \mathrm{O}$ glasses

\section{Captions for figures}

Fig. 1 IR spectra of $\mathrm{Li}_{2} \mathrm{O}-\mathrm{Nb}_{2} \mathrm{O}_{5}-\mathrm{P}_{2} \mathrm{O}_{5}: \mathrm{Ag}_{2} \mathrm{O}$ glasses recorded at room temperature.

Fig. 2 Optical absorption spectra of $\mathrm{Li}_{2} \mathrm{O}-\mathrm{Nb}_{2} \mathrm{O}_{5}-\mathrm{P}_{2} \mathrm{O}_{5}: \mathrm{Ag}_{2} \mathrm{O}$ glasses recorded at room temperature.

Fig. 3 Tauc plots to evaluate optical band gap of $\mathrm{Li}_{2} \mathrm{O}-\mathrm{Nb}_{2} \mathrm{O}_{5}-\mathrm{P}_{2} \mathrm{O}_{5}: \mathrm{Ag}_{2} \mathrm{O}$ glasses.

Fig. 4 (a) Photoluminescence spectra of $\mathrm{Li}_{2} \mathrm{O}-\mathrm{Nb}_{2} \mathrm{O}_{5}-\mathrm{P}_{2} \mathrm{O}_{5}: \mathrm{Ag}_{2} \mathrm{O}$ glasses recorded at room temperature $\left(\lambda_{\text {exc. }}=390 \mathrm{~nm}\right)$.

Fig. 4(b) Deconvoluted XPS spectrum of $3 \mathrm{~d}$ Ag of the glass $\mathrm{A}_{25}$

Fig. 5 (a) Variation of dielectric constant $\varepsilon^{\prime}(\omega)$ with frequency at different temperatures for the glass $\mathrm{A}_{5}$.

Fig. 5(b) Variation of dielectric constant $\varepsilon^{\prime}(\omega)$ with temperature at different frequencies for the glass $\mathrm{A}_{10}$.

Fig. 6(a) Variation of $\tan \delta$ with frequency at different temperatures drawn for the glass $A_{15}$.

Fig. 6(b) Variation of dielectric loss ( $\tan \delta$ ) with temperature for the glass $\mathrm{A}_{20}$.

Figs. 7(a) \& (b) Variations of $M^{\prime}$ and $M^{\prime \prime}$ with frequency at different temperatures for the glass $\mathrm{A}_{15}$.

Figs. 8(a) \& (b) Variations of $M^{\prime}$ and $M^{\prime \prime}$ with temperature at different frequencies for the glass $\mathrm{A}_{20}$.

Fig. 9(a) Variation of $M^{\prime}$ and $M^{\prime \prime}$ with frequency at $363 \mathrm{~K}$ for the sample $\mathrm{A}_{15}$ (b) Variation of relaxation time $\left(\tau_{M}\right)$ with the concentration of $\mathrm{Ag}_{2} \mathrm{O}$ at $363 \mathrm{~K}$ (c) Variation of relaxation time $\left(\tau_{M}\right)$ with temperature drawn for the glass $\mathrm{A}_{15}$.

Fig. 10. Complex impedance plots of glass $\mathrm{A}_{25}$ drawn at different temperatures.

Fig. 11. Comparison plots of impedance spectra for all the glasses drawn at $453 \mathrm{~K}$.

Fig. 12(a). Variation of ac conductivity with frequency for the glass $A_{20}$ drawn at different temperatures. 
Fig. 12(b). Variation of ac conductivity with $1 / \mathrm{T}$ at various frequencies for the glass $\mathrm{A}_{20}$.

Fig. 13. Variation of UDR exponent $s$ with temperature evaluated for the glass $\mathrm{A}_{15}$. Inset shows the variation of $s$ with concentration of $\mathrm{Ag}_{2} \mathrm{O}$ at $393 \mathrm{~K}$.

Fig. 14. The compositional dependence of $\sigma_{a c}$ at $363 \mathrm{~K}$ and activation energy, $W_{a c}$ for all glass samples. 
Table 1. Composition (all in mol\%) and thickness of the glass samples used.

\begin{tabular}{cccccc}
\hline Glass & $\mathrm{Li}_{2} \mathrm{O}$ & $\mathrm{Nb}_{2} \mathrm{O}_{5}$ & $\mathrm{P}_{2} \mathrm{O}_{5}$ & $\mathrm{Ag}_{2} \mathrm{O}$ & $\begin{array}{c}\text { Thickness } \\
(\mathrm{mm})\end{array}$ \\
\hline $\mathrm{A}_{0}$ & 35 & 5 & 60.0 & 0 & 1.874 \\
$\mathrm{~A}_{5}$ & 35 & 5 & 59.5 & 0.5 & 1.911 \\
$\mathrm{~A}_{10}$ & 35 & 5 & 59.0 & 1.0 & 1.608 \\
$\mathrm{~A}_{15}$ & 35 & 5 & 58.5 & 1.5 & 2.097 \\
$\mathrm{~A}_{20}$ & 35 & 5 & 58.0 & 2.0 & 1.875 \\
$\mathrm{~A}_{25}$ & 35 & 5 & 57.5 & 2.5 & 1.908 \\
\hline
\end{tabular}

Table 2. Physical properties of $\mathrm{Li}_{2} \mathrm{O}-\mathrm{Nb}_{2} \mathrm{O}_{5}-\mathrm{P}_{2} \mathrm{O}_{5}: \mathrm{Ag}_{2} \mathrm{O}$ glasses.

\begin{tabular}{lllllll}
\hline Glass $\rightarrow$ & $\mathrm{A}_{0}$ & $\mathrm{~A}_{5}$ & $\mathrm{~A}_{10}$ & $\mathrm{~A}_{15}$ & $\mathrm{~A}_{20}$ & $\mathrm{~A}_{25}$
\end{tabular}

Physical property

\begin{tabular}{lllllll}
\hline Density $d\left(\mathrm{~g} / \mathrm{cm}^{3}\right)( \pm 0.0001$ & 2.1205 & 2.5759 & 2.6032 & 2.6319 & 2.6412 & 2.6547 \\
Silver ion conc. $N_{\mathrm{i}}\left(\mathrm{x} 10^{21}, \mathrm{~cm}^{-3}\right)$ & - & 7.09 & 7.14 & 7.19 & 7.18 & 7.19 \\
$\begin{array}{l}\text { Inter ionic distance } \\
\text { of } \mathrm{Ag}^{+} \text {ions } r_{\mathrm{i}}(\AA)( \pm 0.01 \AA)\end{array}$ & - & 24.15 & 24.10 & 24.04 & 24.05 & 24.04 \\
& & & & & & \\
Polaron radius $r_{\mathrm{p}}(\AA)( \pm 0.01 \AA)$ & - & 9.695 & 9.712 & 9.689 & 9.694 & 9.689 \\
\end{tabular}


Table 3. Optical absorption data of $\mathrm{Li}_{2} \mathrm{O}-\mathrm{Nb}_{2} \mathrm{O}_{5}-\mathrm{P}_{2} \mathrm{O}_{5}: \mathrm{Ag}_{2} \mathrm{O}$ glasses

\begin{tabular}{lllllll}
\hline Glass $\rightarrow$ & $\mathrm{A}_{0}$ & $\mathrm{~A}_{5}$ & $\mathrm{~A}_{10}$ & $\mathrm{~A}_{15}$ & $\mathrm{~A}_{20}$ & $\mathrm{~A}_{25}$ \\
\hline Absorption edge $(\mathrm{nm})$ & 316 & 318 & 325 & 321 & 291 & 306 \\
SPR band position $(\mathrm{nm})$ & - & 420.0 & 418.9 & 421.1 & 422.2 & 422.7 \\
& & & & & & \\
Optical band gap, $E_{o}(\mathrm{eV})$ & 3.88 & 3.89 & 3.92 & 3.72 & 3.78 & 3.82 \\
\hline
\end{tabular}

Table 4. Selected parameters evaluated from dielectric studies on $\mathrm{Li}_{2} \mathrm{O}-\mathrm{Nb}_{2} \mathrm{O}_{5}-\mathrm{P}_{2} \mathrm{O}_{5}: \mathrm{Ag}_{2} \mathrm{O}$ glasses

\begin{tabular}{cccc}
\hline Glass & $\begin{array}{c}\text { Activation energy for } \\
\text { ac conduction, } W_{\mathrm{ac}}(\mathrm{eV}) \\
( \pm 0.01)\end{array}$ & $\begin{array}{c}\text { Activation energy for } \\
\text { dipoles, } W_{\mathrm{d}}(\mathrm{eV}) \\
( \pm 0.01)\end{array}$ & $\begin{array}{c}\mathrm{N}\left(E_{F}\right) \\
(\mathrm{x} \mathrm{10}) \\
( \pm 0.01)\end{array}$ \\
\hline $\mathrm{A}_{5}$ & 0.84 & 2.26 & 6.68 \\
$\mathrm{~A}_{10}$ & 0.98 & 2.59 & 5.87 \\
$\mathrm{~A}_{15}$ & 0.85 & 2.28 & 6.35 \\
$\mathrm{~A}_{20}$ & 0.92 & 2.35 & 6.04 \\
$\mathrm{~A}_{25}$ & 0.95 & 2.48 & 5.93 \\
\hline
\end{tabular}




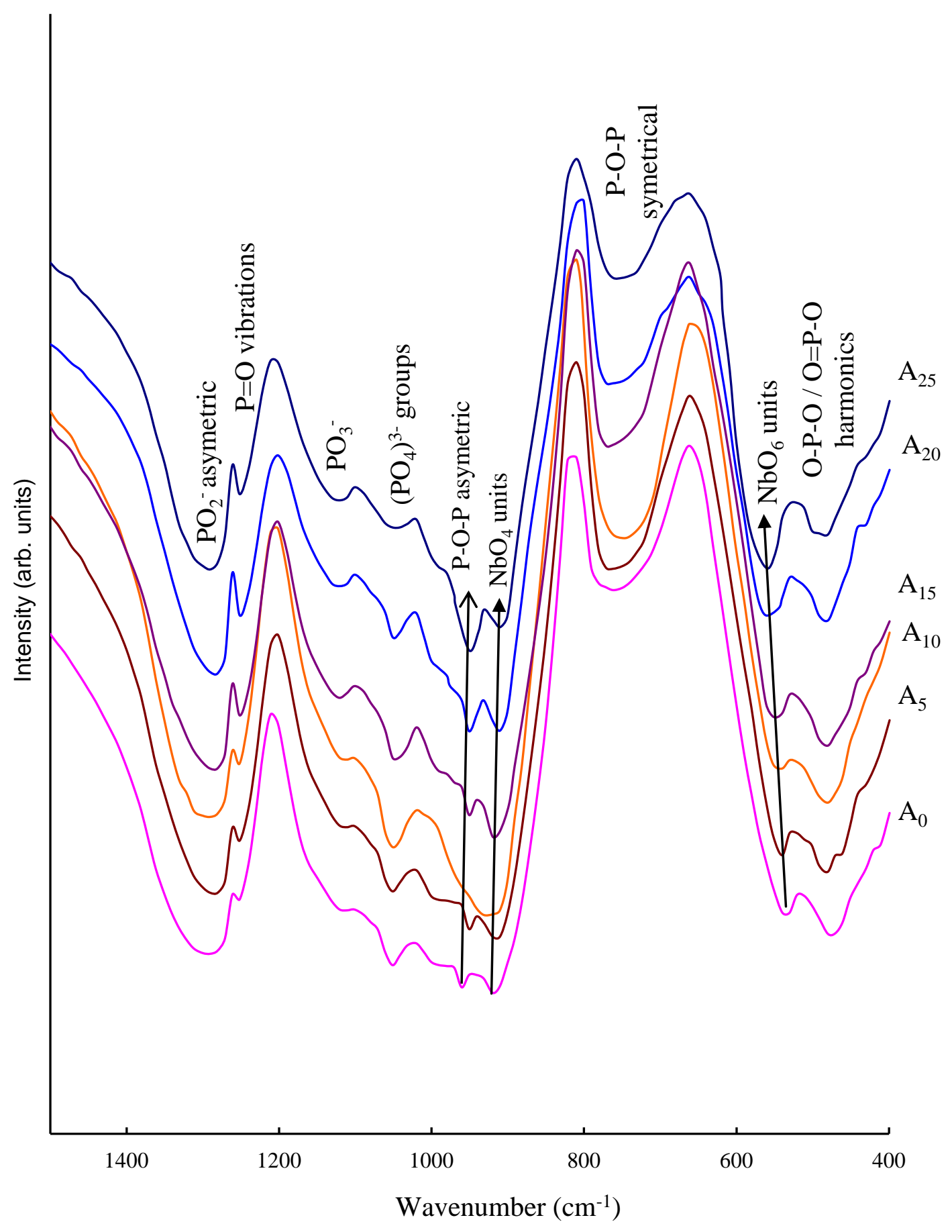

Fig. 1 IR spectra of $\mathrm{Li}_{2} \mathrm{O}-\mathrm{Nb}_{2} \mathrm{O}_{5}-\mathrm{P}_{2} \mathrm{O}_{5}: \mathrm{Ag}_{2} \mathrm{O}$ glasses recorded at room temperature. 


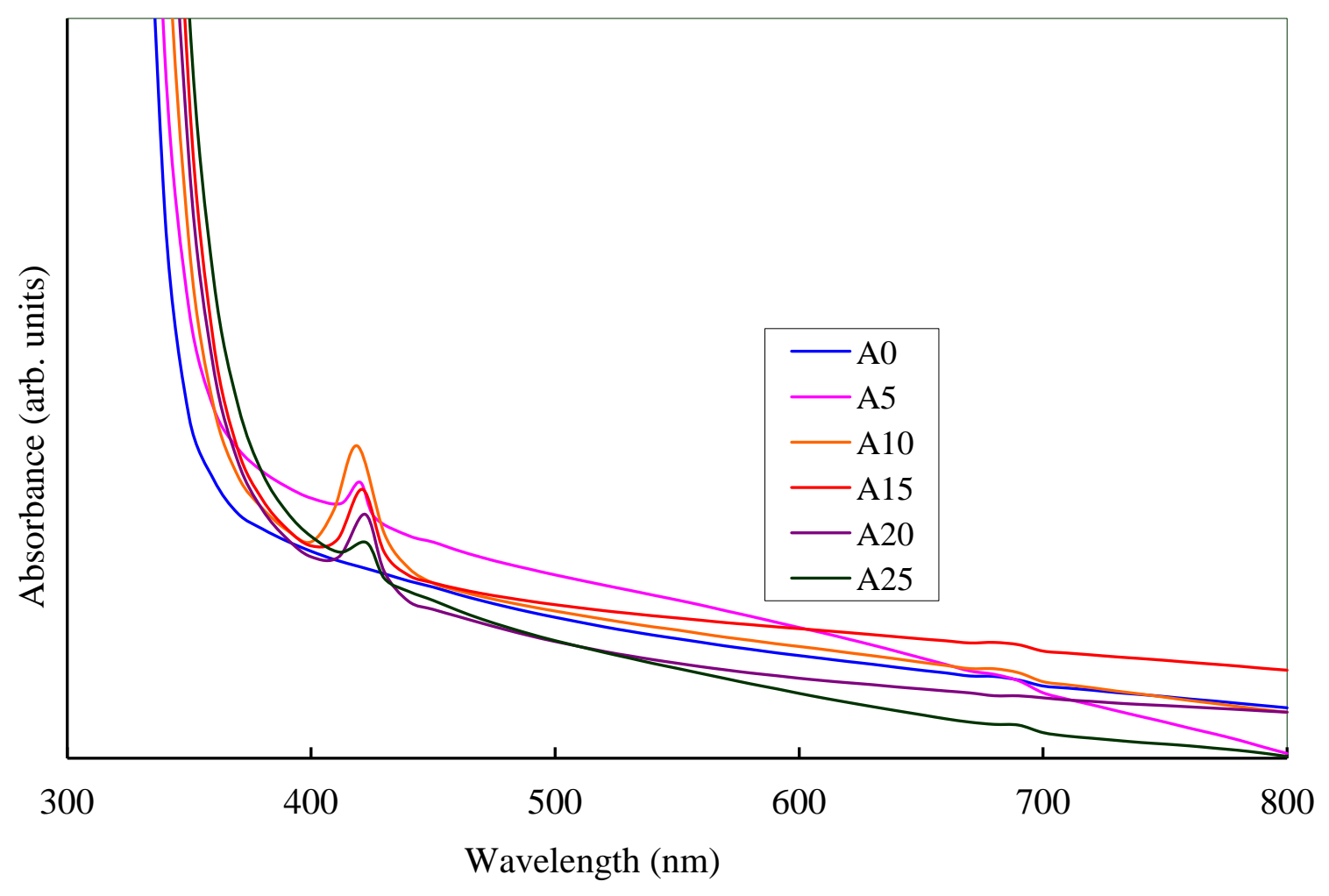

Fig. 2 Optical absorption spectra of $\mathrm{Li}_{2} \mathrm{O}-\mathrm{Nb}_{2} \mathrm{O}_{5}-\mathrm{P}_{2} \mathrm{O}_{5}: \mathrm{Ag}_{2} \mathrm{O}$ glasses recorded at room temperature. 


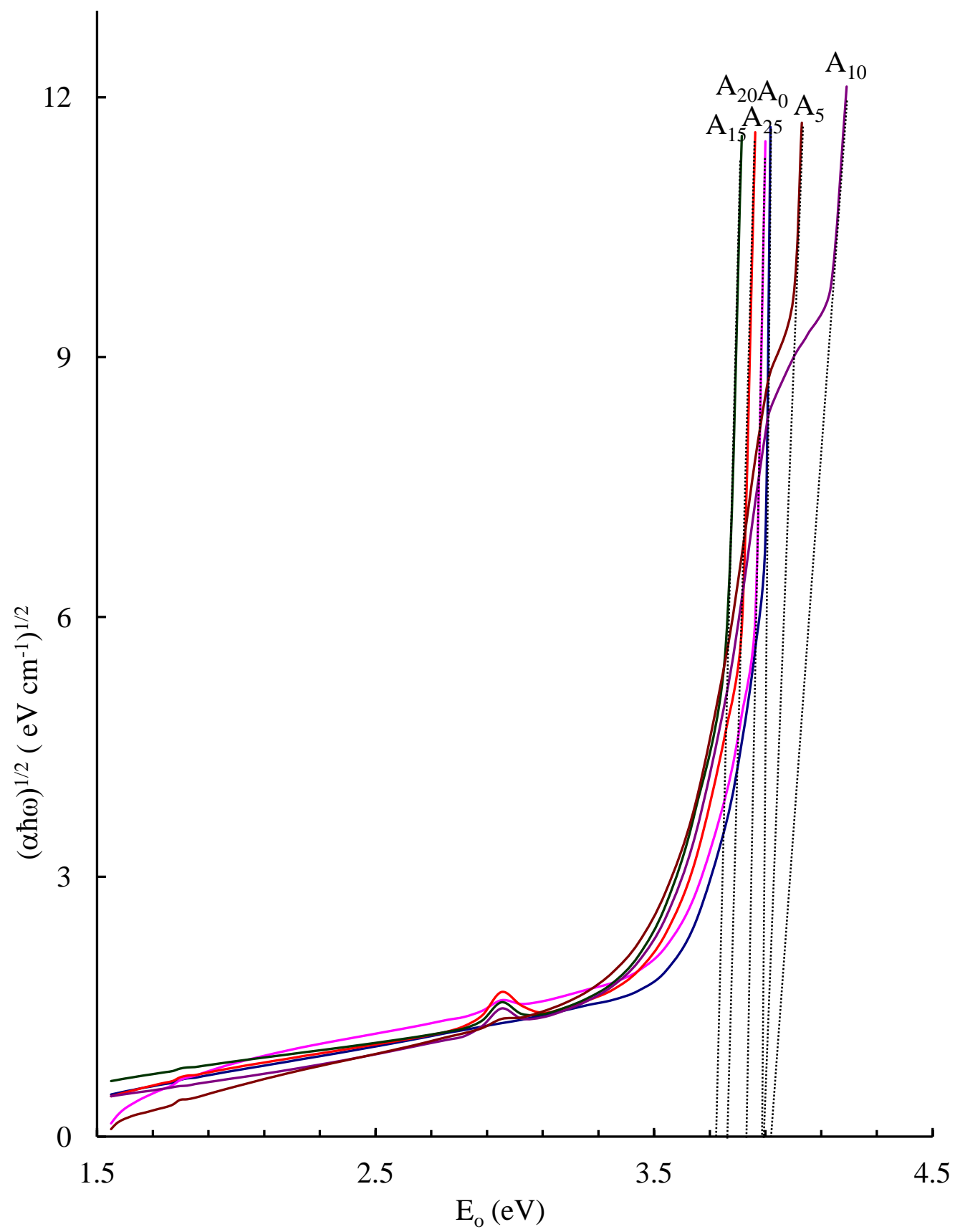

Fig. 3 Tauc plots to evaluate optical band gap of $\mathrm{Li}_{2} \mathrm{O}-\mathrm{Nb}_{2} \mathrm{O}_{5}-\mathrm{P}_{2} \mathrm{O}_{5}: \mathrm{Ag}_{2} \mathrm{O}$ glasses. 


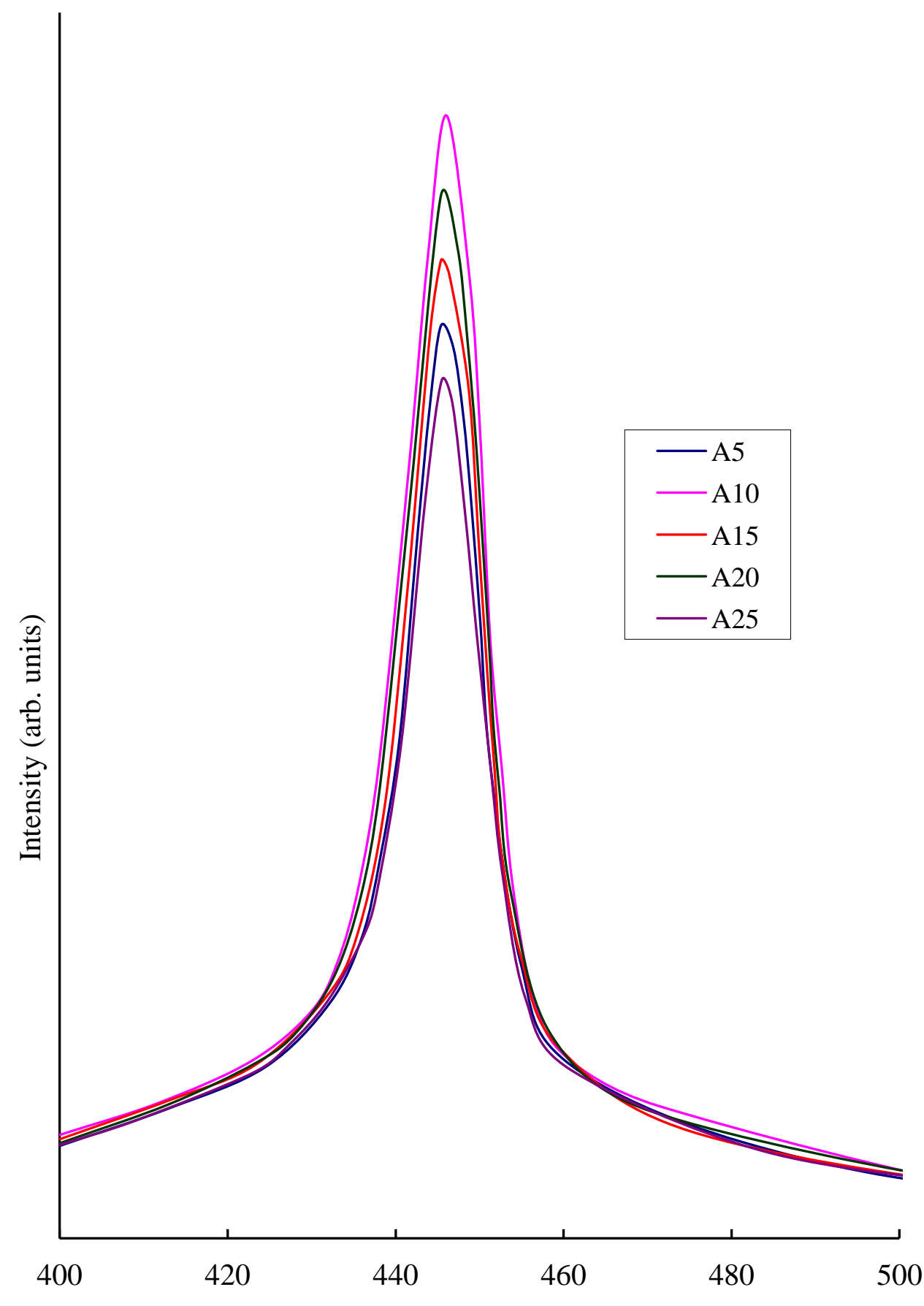

Wavelength, $\lambda(\mathrm{nm})$

Fig. 4 (a) Photoluminescence spectra of $\mathrm{Li}_{2} \mathrm{O}-\mathrm{Nb}_{2} \mathrm{O}_{5}-\mathrm{P}_{2} \mathrm{O}_{5}: \mathrm{Ag}_{2} \mathrm{O}$ glasses recorded at room temperature $\left(\lambda_{\text {exc. }}=390 \mathrm{~nm}\right)$. 


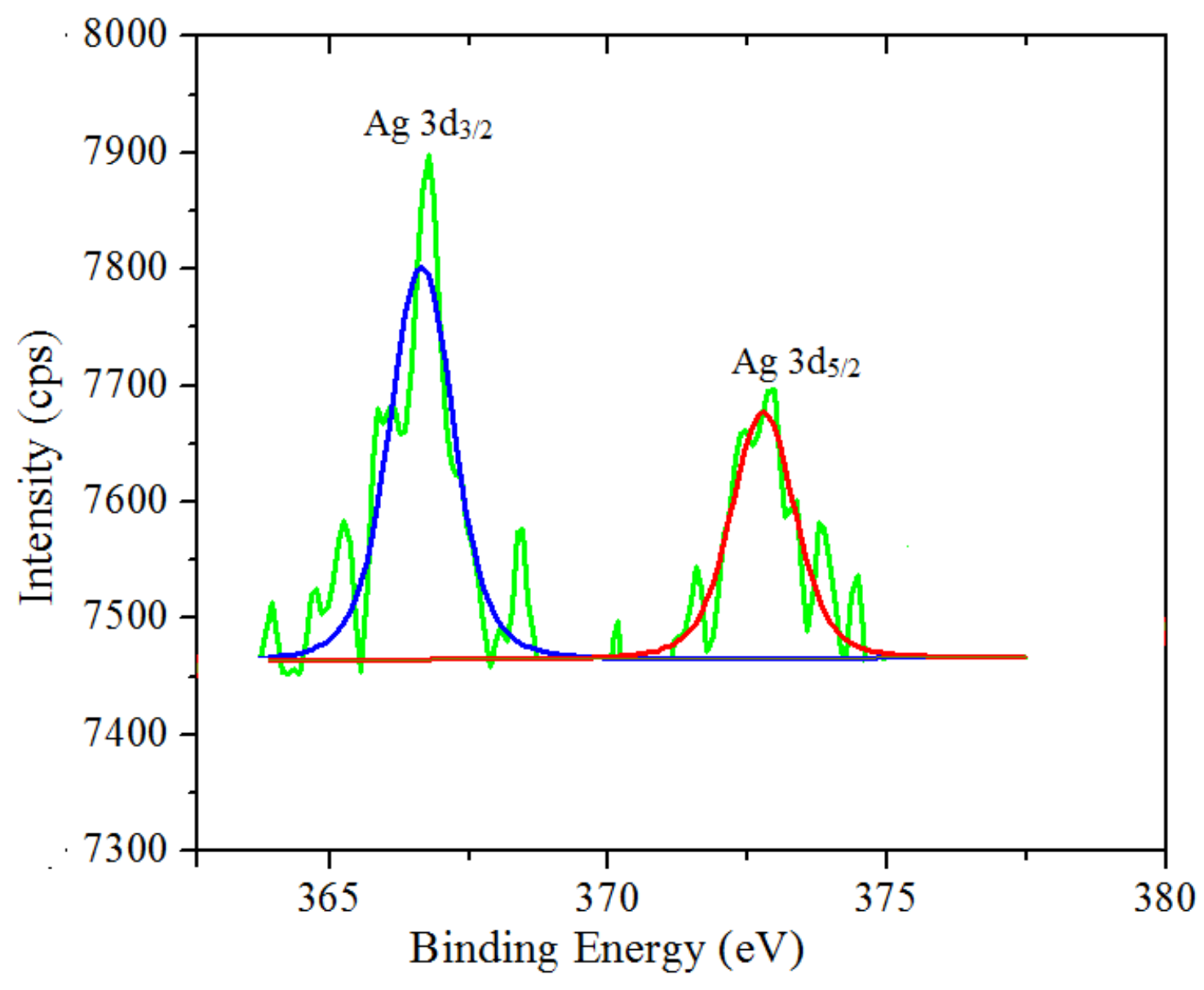

Fig. 4(b) Deconvoluted XPS spectrum of $3 \mathrm{~d}$ Ag of the glass $\mathrm{A}_{25}$ 


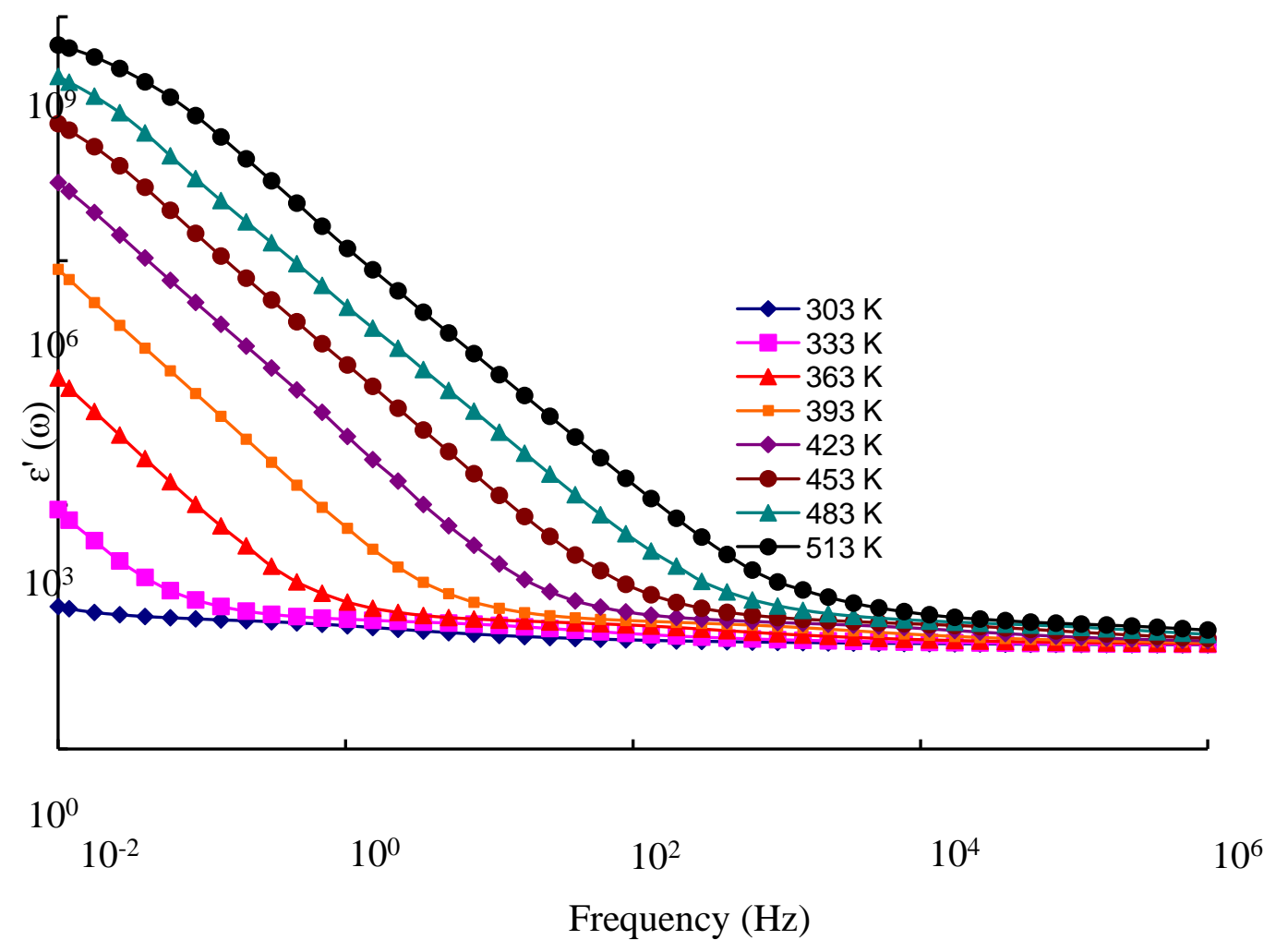

Fig. 5 (a) Variation of dielectric constant $\varepsilon^{\prime}(\omega)$ with frequency at different temperatures for the glass $\mathrm{A}_{5}$. 


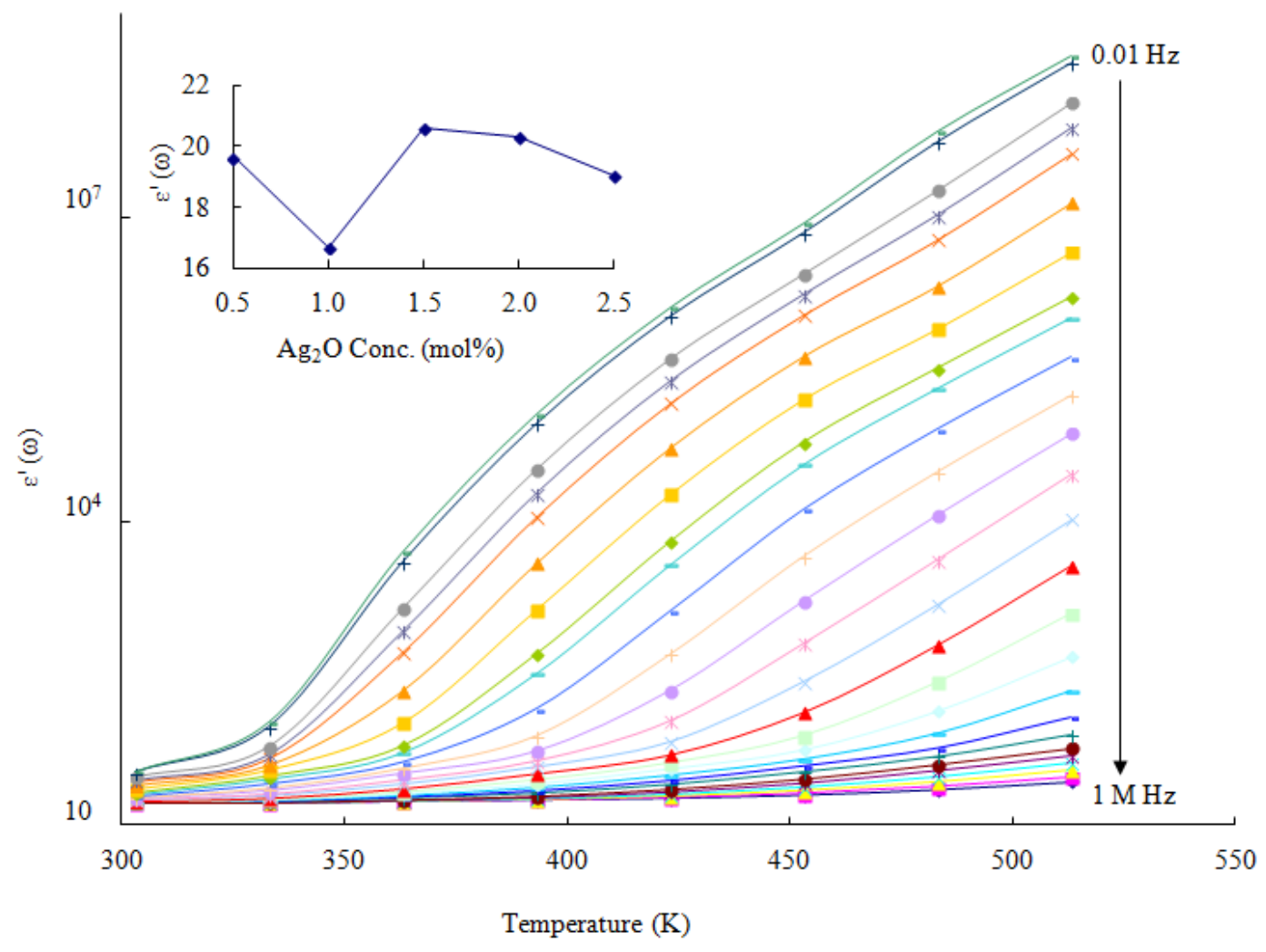

Fig. 5(b) Variation of dielectric constant $\varepsilon^{\prime}(\omega)$ with temperature at different frequencies for the glass $\mathrm{A}_{10}$. 


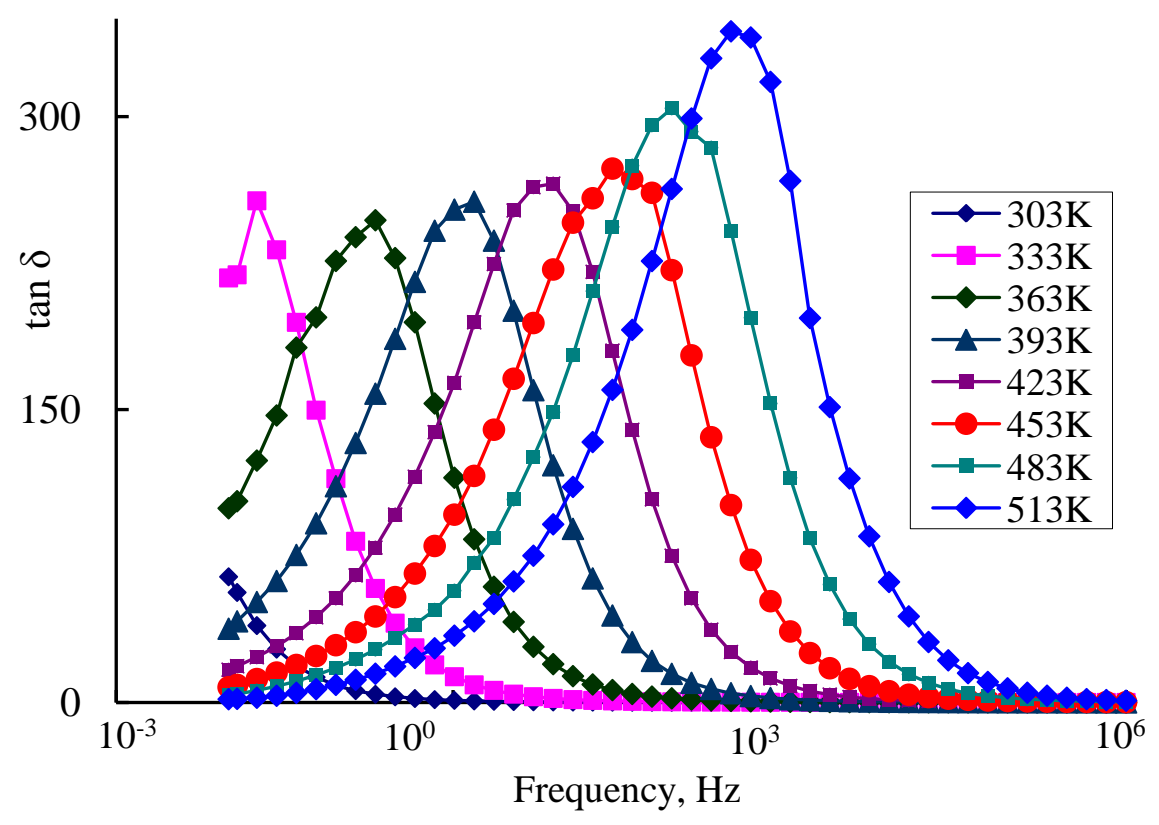

Fig. 6(a) Variation of $\tan \delta$ with frequency at different temperatures drawn for the glass $A_{15}$. 


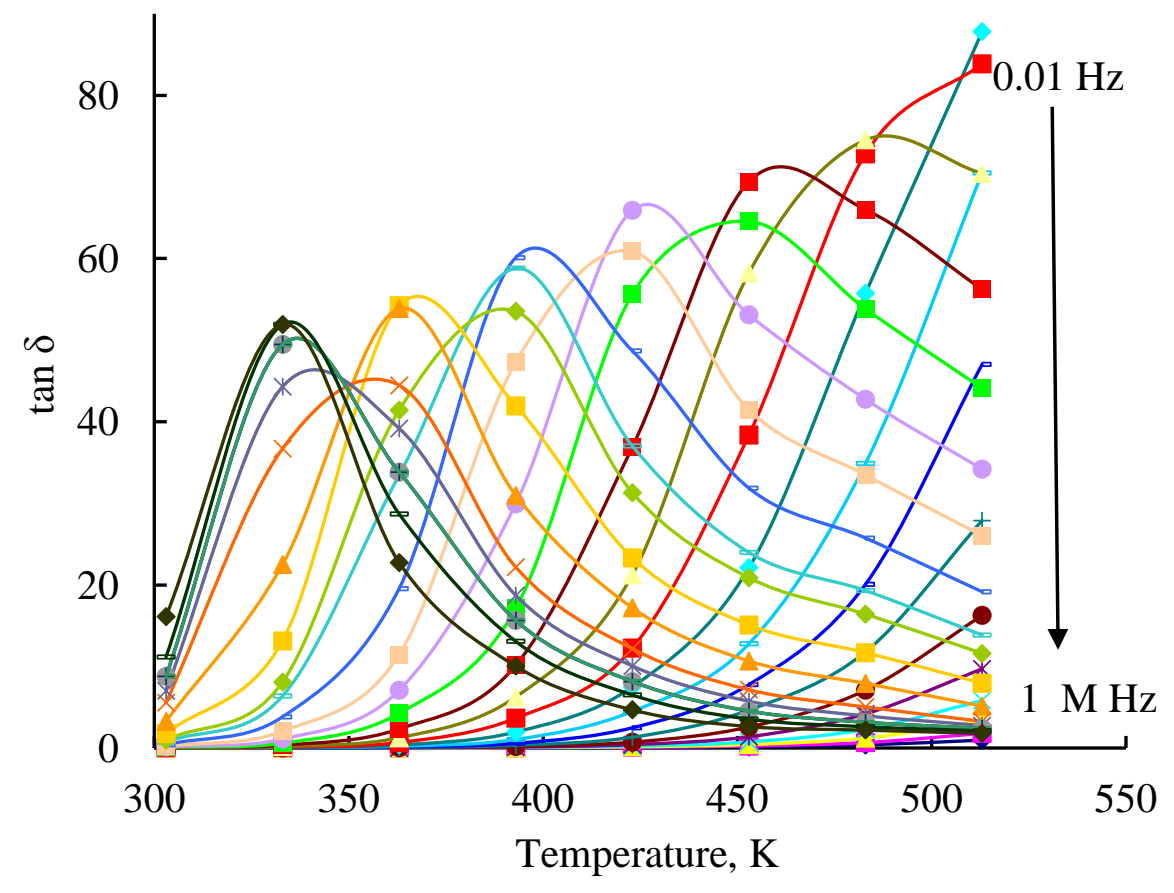

Fig. 6(b) Variation of dielectric loss $\left(\tan \delta\right.$ ) with temperature for the glass $\mathrm{A}_{20}$. 

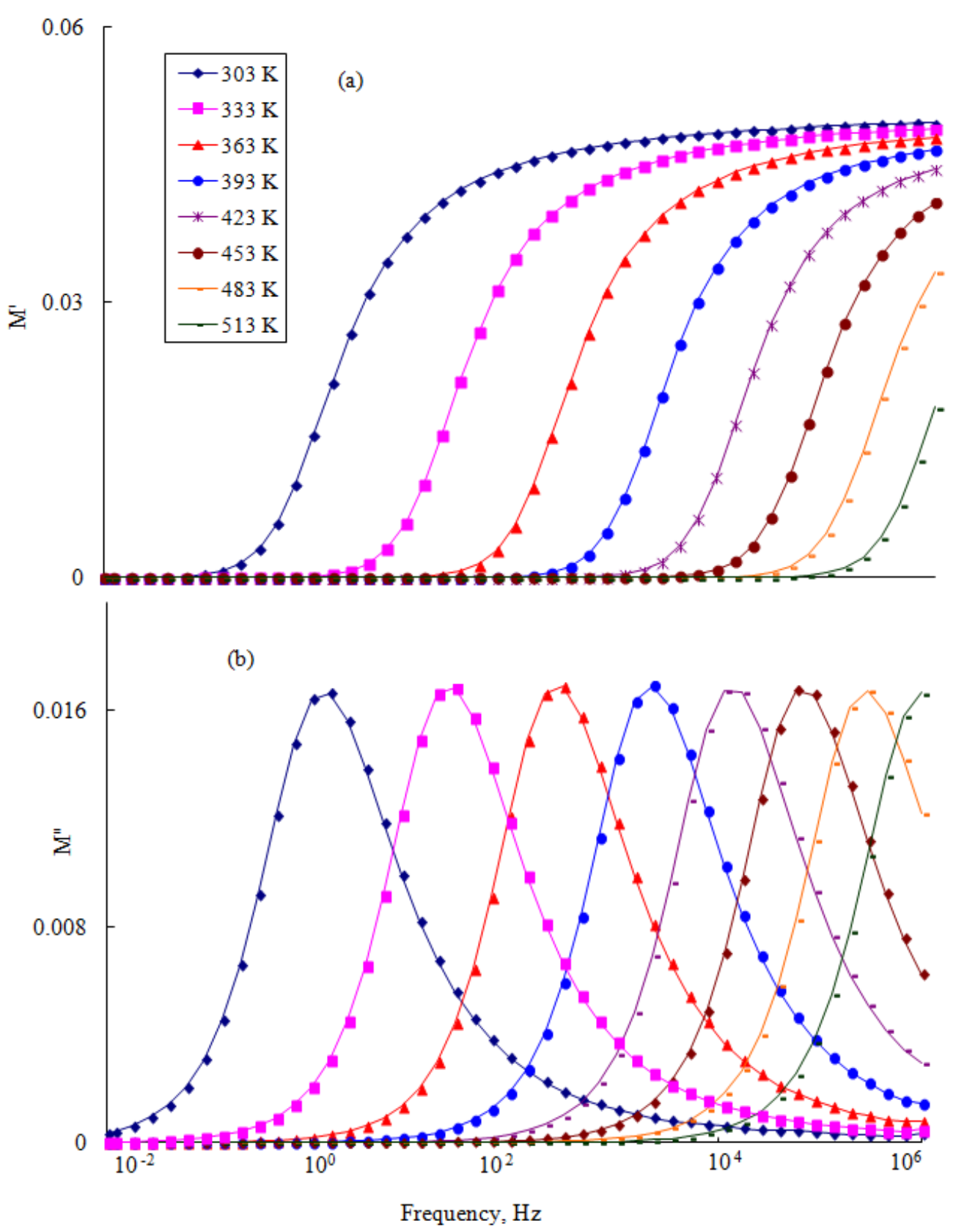

Figs. 7(a) \& (b) Variations of $M^{\prime}$ and $M^{\prime \prime}$ with frequency at different temperatures for the glass $A_{15}$. 

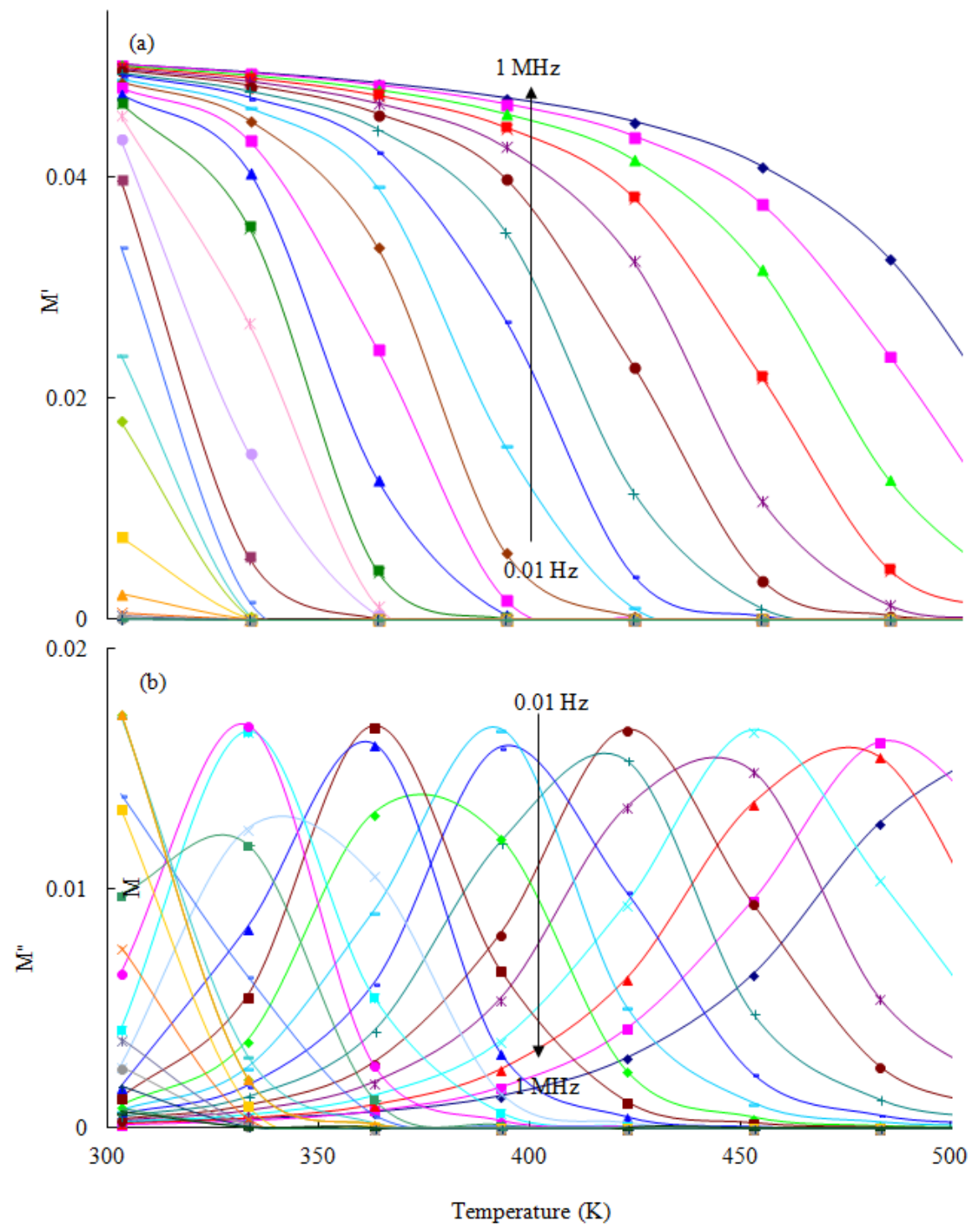

Figs. 8(a) \& (b) Variations of $M^{\prime}$ and $M^{\prime \prime}$ with temperature at different frequencies for the glass $A_{20}$. 


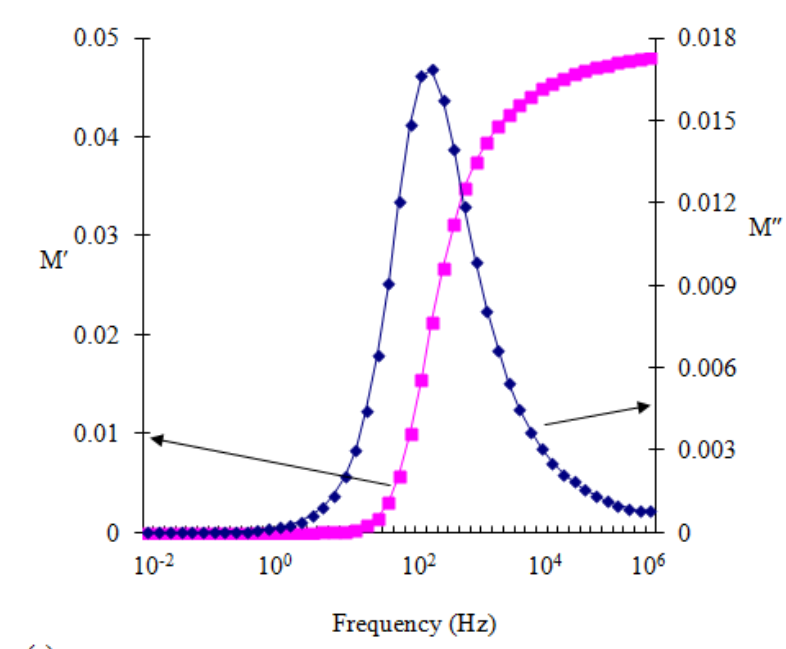

(a)
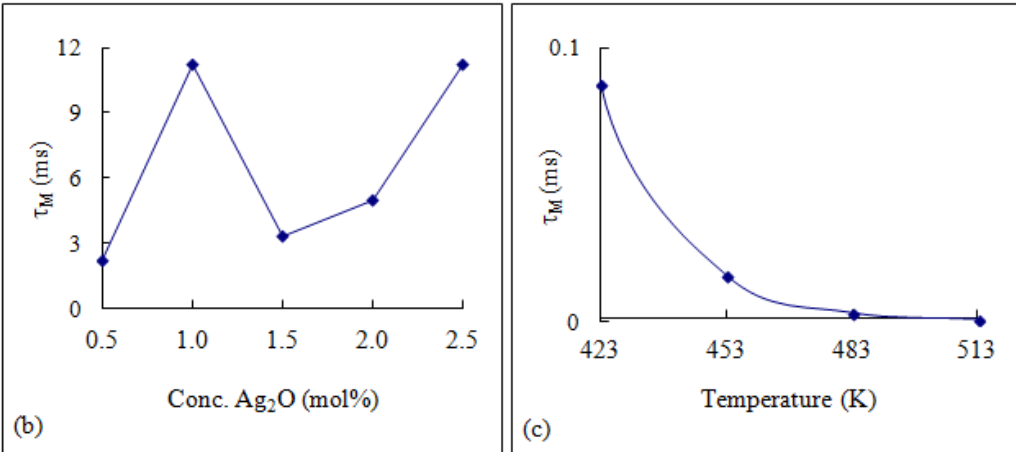

Fig. 9(a) Variation of $M^{\prime}$ and $M^{\prime \prime}$ with frequency at $363 \mathrm{~K}$ for the sample $\mathrm{A}_{15}$ (b) Variation of relaxation time $\left(\tau_{M}\right)$ with the concentration of $\mathrm{Ag}_{2} \mathrm{O}$ at $363 \mathrm{~K}$ (c) Variation of relaxation time $\left(\tau_{M}\right)$ with temperature drawn for the glass $\mathrm{A}_{15}$. 


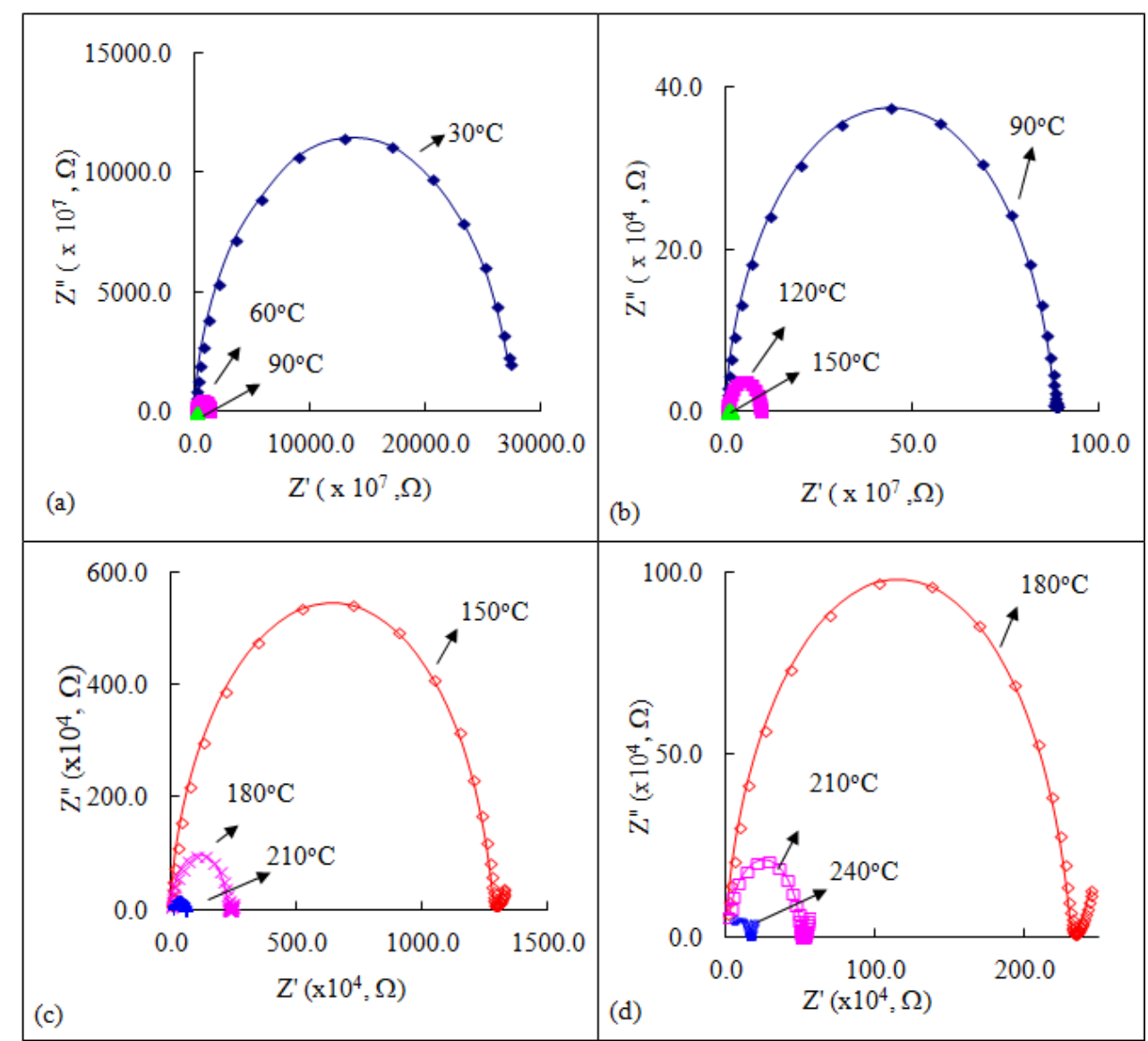

Fig. 10. Complex impedance plots of glass $A_{25}$ drawn at different temperatures. 


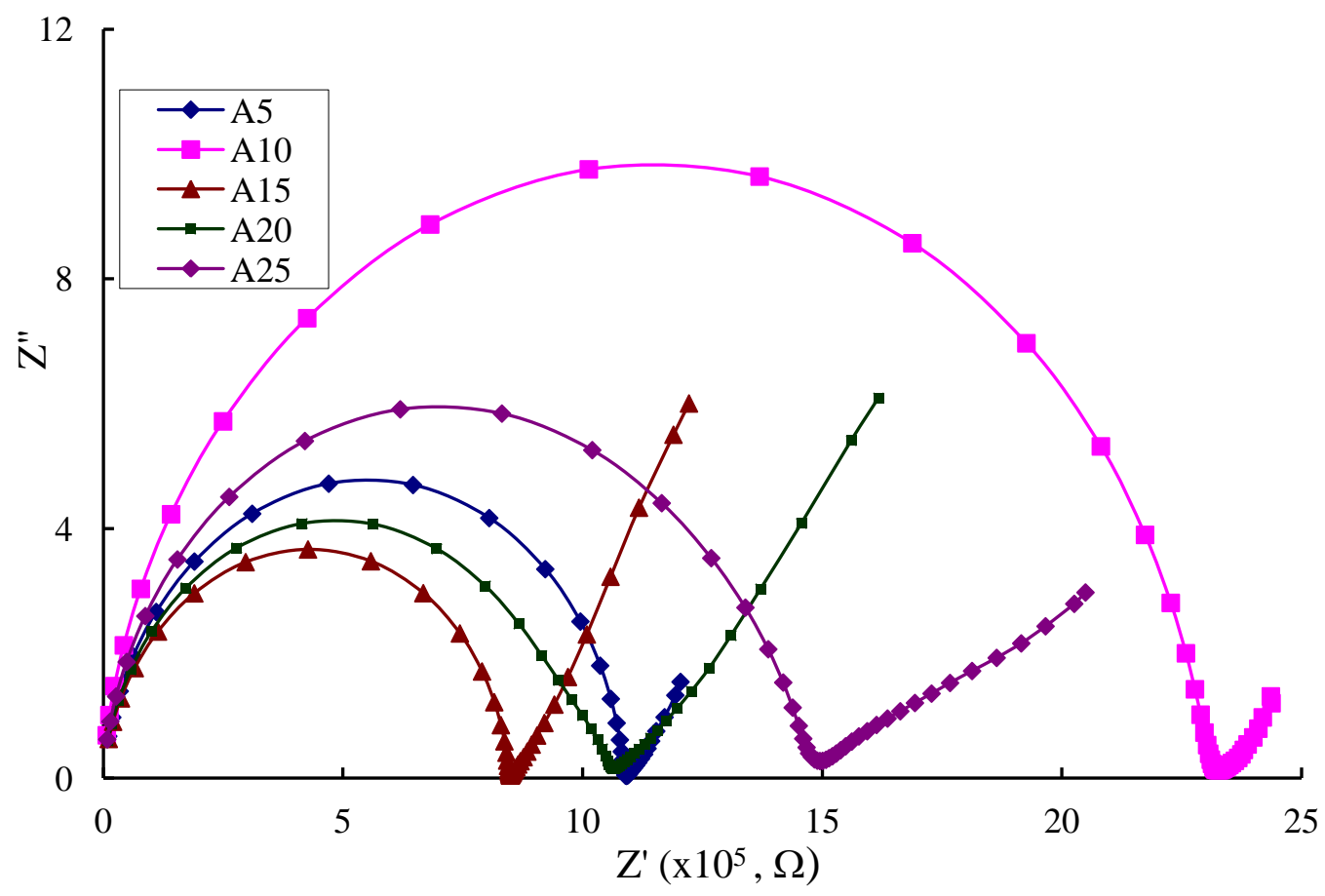

Fig. 11. Comparison plots of impedance spectra for all the glasses drawn at $453 \mathrm{~K}$. 


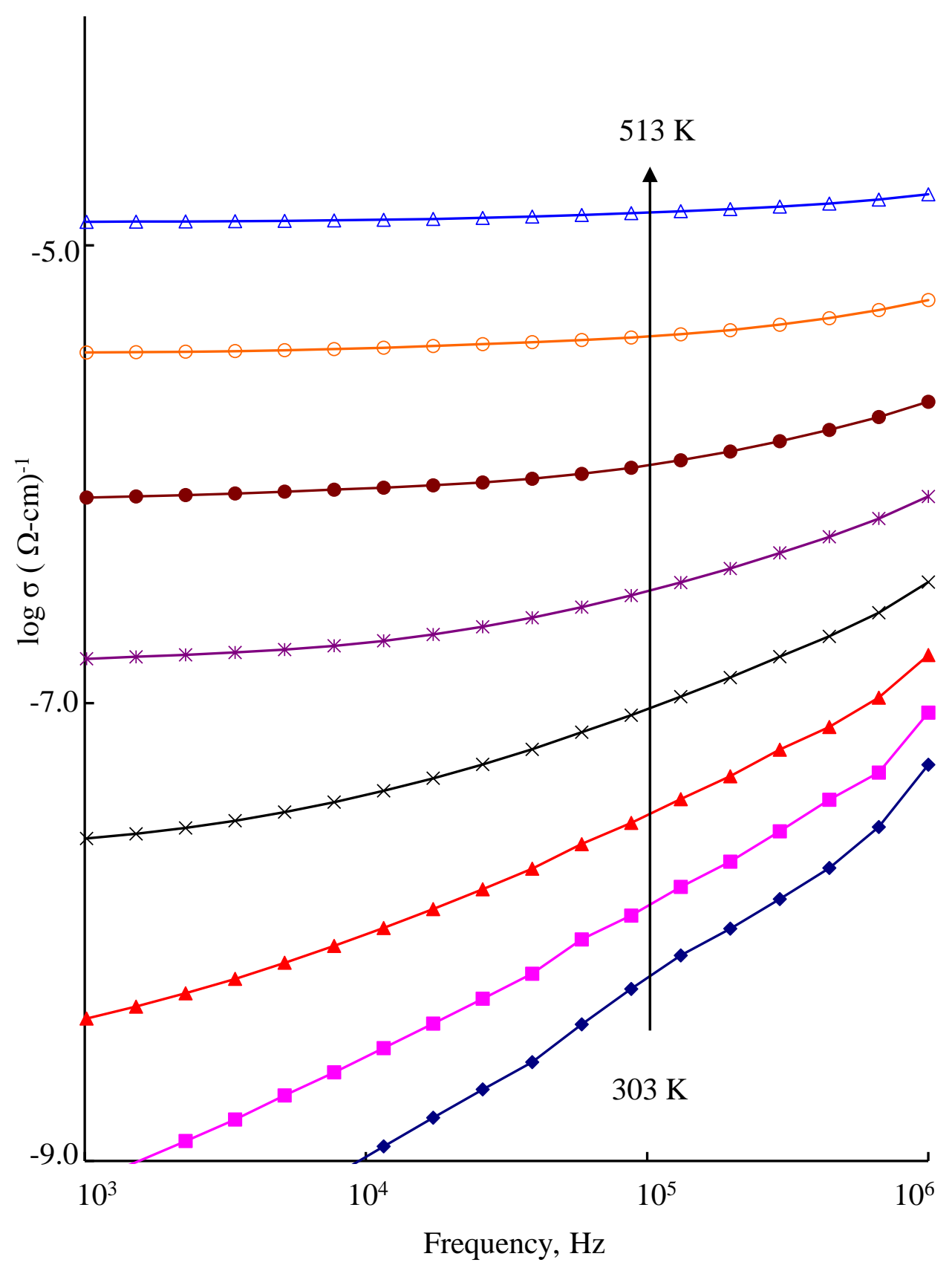

Fig. 12(a). Variation of ac conductivity with frequency for the glass $A_{20}$ drawn at different temperatures. 


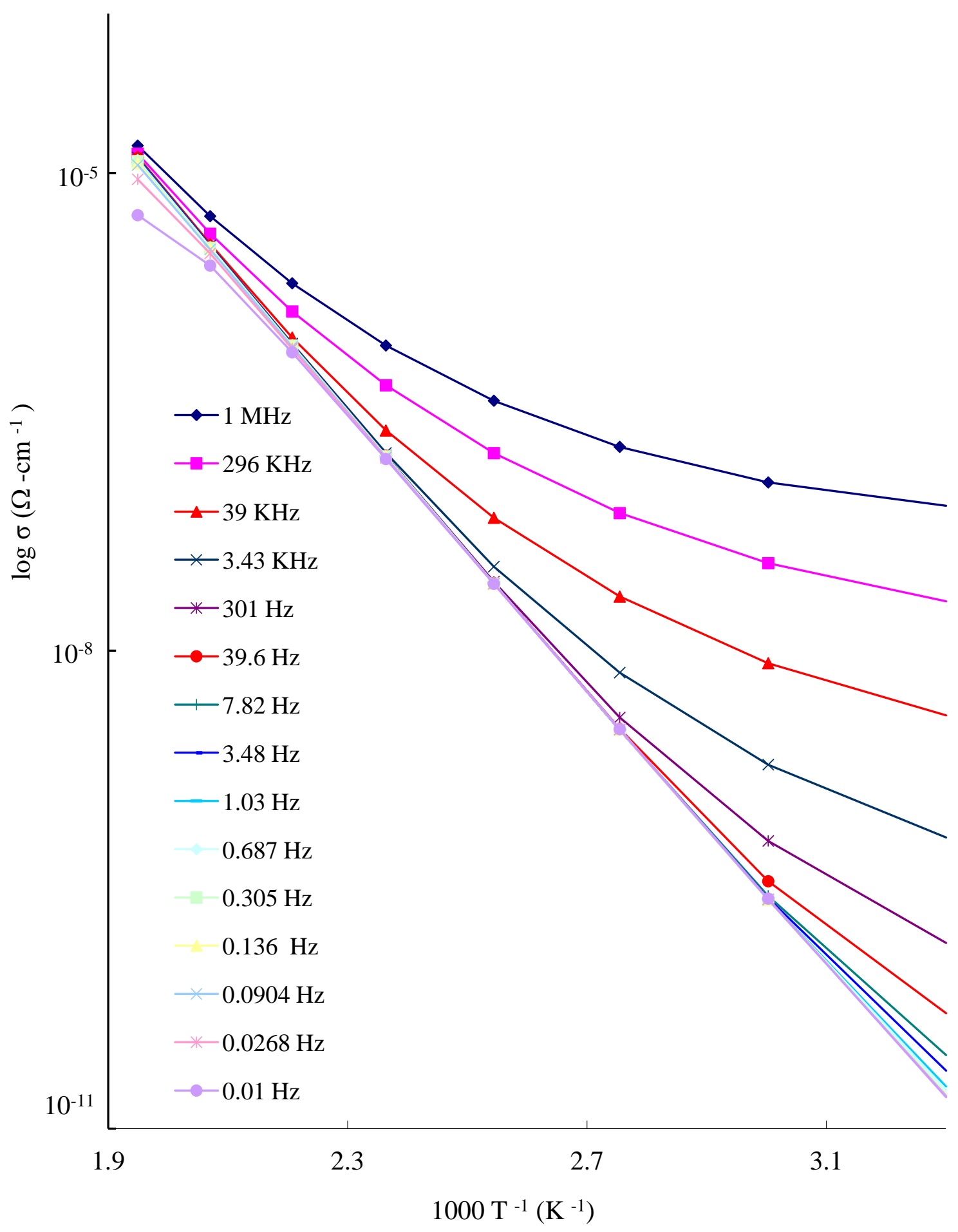

Fig. 12(b). Variation of ac conductivity with $1 / \mathrm{T}$ at various frequencies for the glass $A_{20}$. 


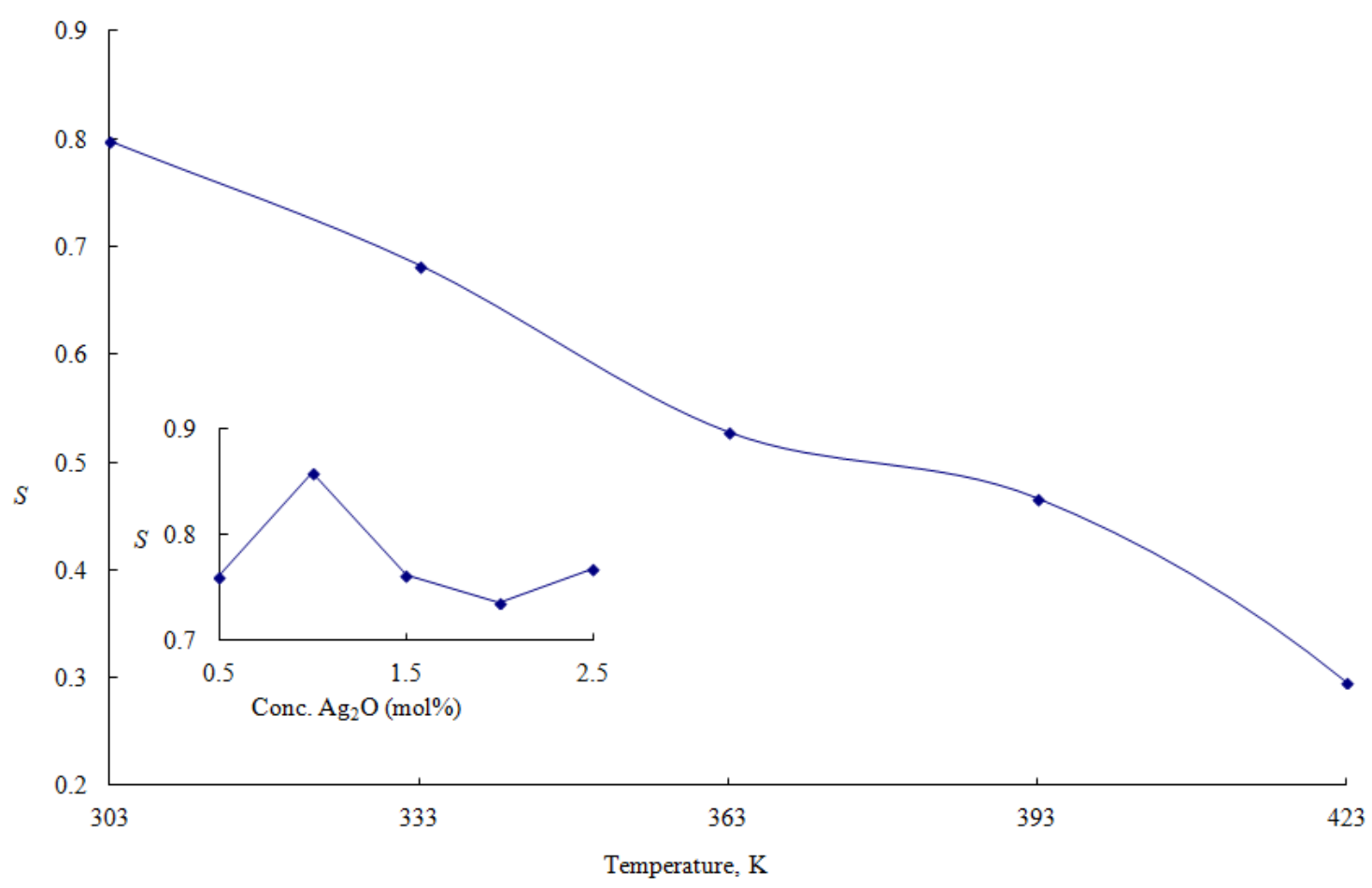

Fig. 13. Variation of UDR exponent $s$ with temperature evaluated for the glass $\mathrm{A}_{15}$. Inset shows the variation of $s$ with concentration of $\mathrm{Ag}_{2} \mathrm{O}$ at $393 \mathrm{~K}$. 


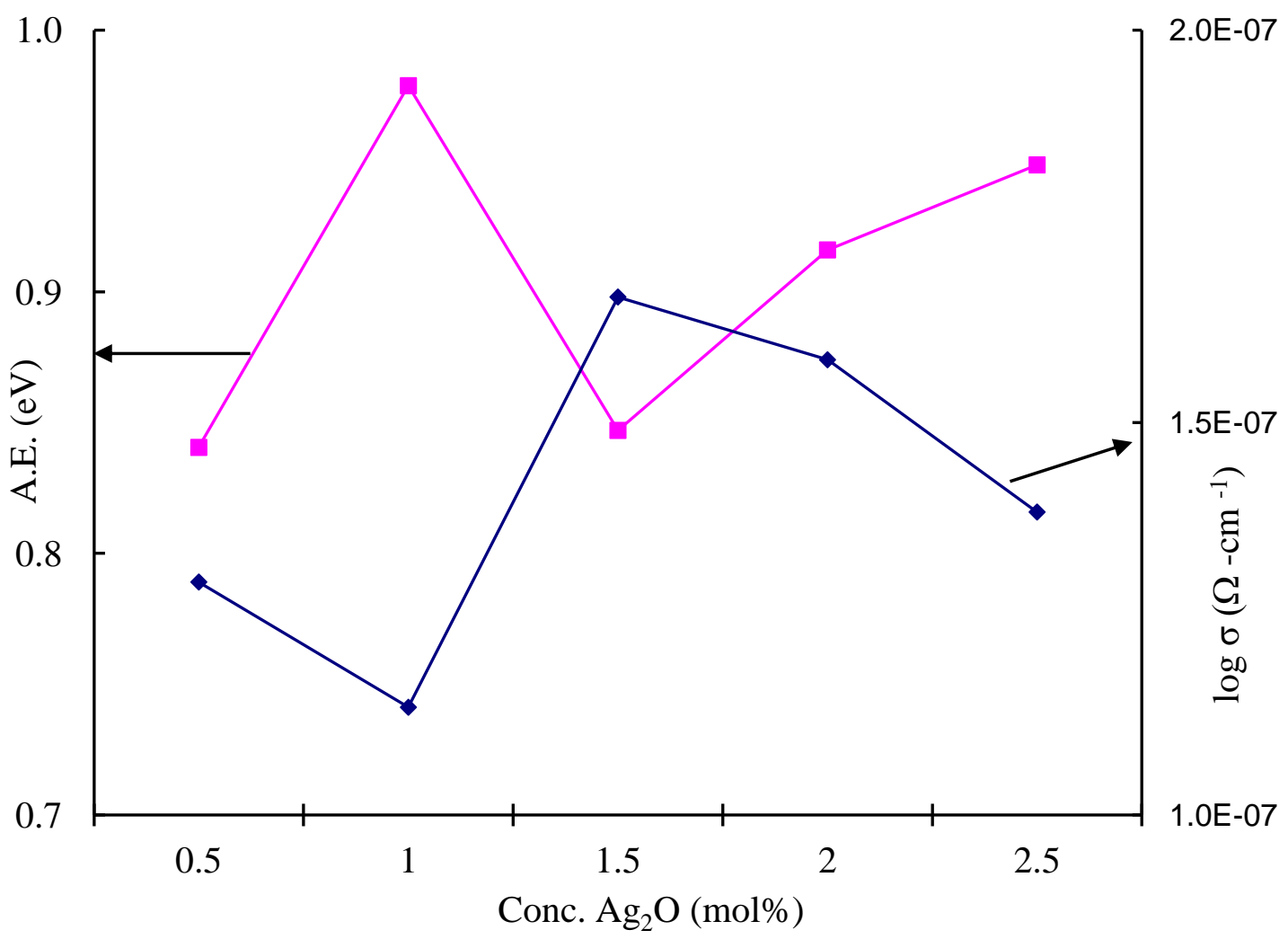

Fig. 14. The compositional dependence of $\sigma_{a c}$ at $363 \mathrm{~K}$ and activation energy, $W_{a c}$ for all glass samples. 
Graphical Abstract (for review)

Graphical abstract
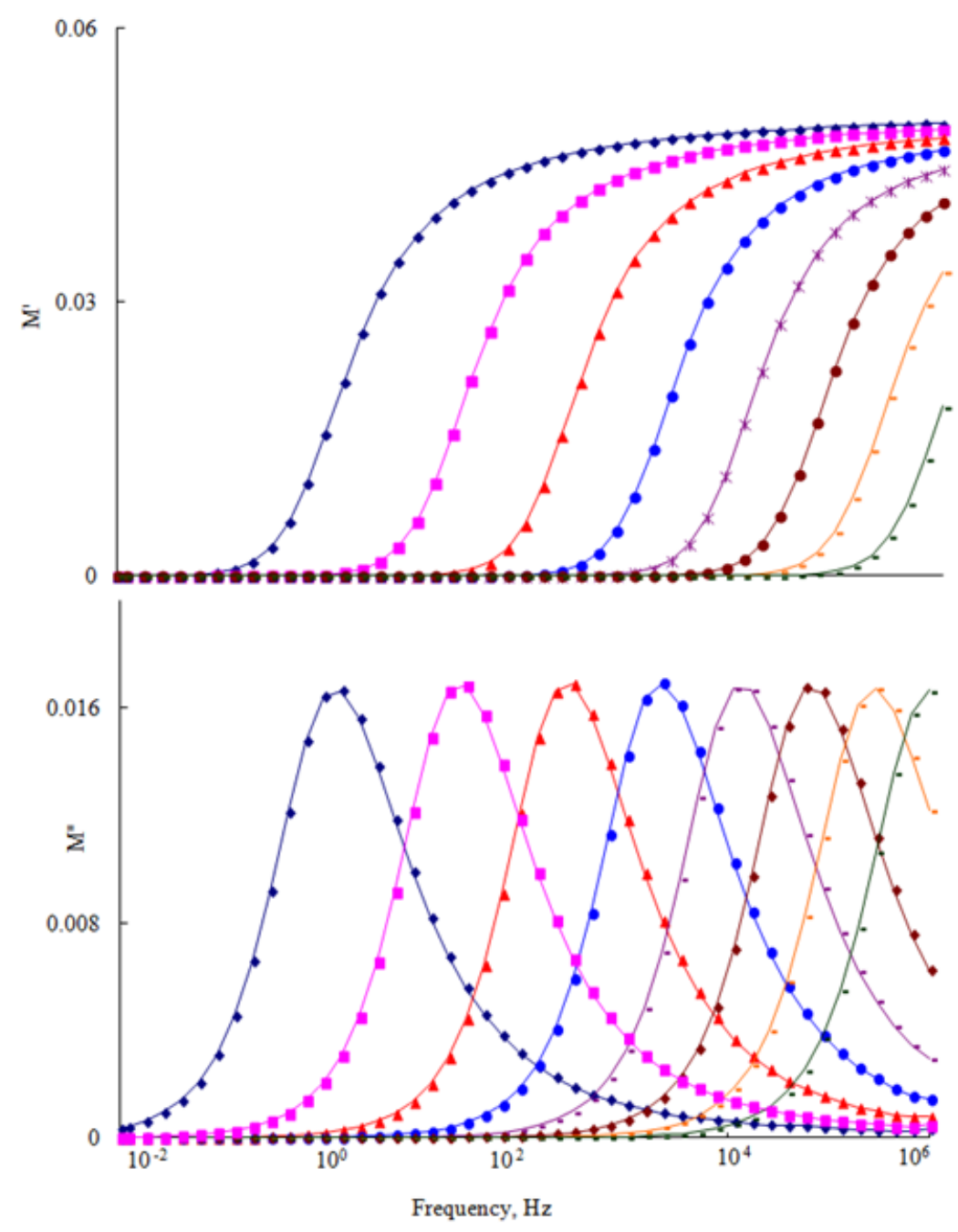


\section{Research Highlights}

- Dielectric properties of $\mathrm{Li}_{2} \mathrm{O}-\mathrm{Nb}_{2} \mathrm{O}_{5}-\mathrm{P}_{2} \mathrm{O}_{5}: \mathrm{Ag}_{2} \mathrm{O}$ glasses were investigated

- Results were analyzed with the aid of data on spectroscopic studies

- Glass with more than $1.0 \mathrm{~mol} \%$ of $\mathrm{Ag}_{2} \mathrm{O}$ exhibited predominantly ionic conductivity

- Such glasses may be useful as electrolytes for ion conducting batteries. 